\title{
SPRINGS: DNA BARCODING OF CADDISFLIES (INSECTA, TRICHOPTERA) IN CROATIA WITH NOTES ON TAXONOMY AND CONSERVATION BIOLOGY
}

Mladen KuČinić ${ }^{*}$, AnĐela Ćukušić ${ }^{2}$, Sanja Žalac $^{3}$, Antun Delić ${ }^{4}$ Darko Cerjanec ${ }^{5}$, Martina Podnar ${ }^{6}$, Renata ĆuK $^{7}$, Ivan VučKović ${ }^{8}$, Ana Previšić ${ }^{,}$Marijana Vuković ${ }^{6}$, Svjetlana Stanić Koštroman ${ }^{9}$, Višnja Bukvić ${ }^{10}$, Ana Šalinović ${ }^{11}$ \& Mladen Plantak ${ }^{8}$

${ }^{1}$ Department of Biology ( ${ }^{*}$ Laboratory for Entomology), Faculty of Science, University of Zagreb, Rooseveltov trg 6, 10000 Zagreb, Croatia

${ }^{2}$ Ministry of Environment and Energy, Radnička cesta 80/7, 10000 Zagreb, Croatia

${ }^{3}$ ZSC „Dr. Ivo Pevalek“, Plitvice Lakes National Park, Josipa Jovića 19, 53231 Plitvička jezera, Croatia

${ }^{4}$ Nikole Šubića Zrinskog 3, 43290 Grubišno Polje, Croatia

${ }^{5}$ Barilović Primary school, Barilović 96, 47252 Barilović, Croatia

${ }^{6}$ Croatian Natural History Museum, Demetrova 1, 10000 Zagreb, Croatia

${ }^{7}$ Hrvatske vode, Central Water Management Laboratory, Ulica grada Vukovara 220, 10000 Zagreb, Croatia

${ }^{8}$ Elektroprojekt d.d., Civil and Architectural Engineering Department, Water Resources, Nature and Environmental Protection, Alexandera von Humboldta 4, 10000 Zagreb, Croatia

${ }^{9}$ Department of Biology, Faculty of Science and Education, University of Mostar, Matice hrvatske, 88000 Mostar, Bosnia and Herzegovina

${ }^{10}$ University of Hercegovina, Blajburških žrtava 100, 88000 Mostar, Bosnia and Herzegovina

${ }^{11}$ Postelska ulica 10, 2000 Maribor, Slovenia

Kučinić, M., Ćukušić, A., Žalac, S., Delić, A., Cerjanec, D., Podnar, M., Ćuk, R., Vučković, I., Previšić A., Vuković M., Stanić Koštroman S., Bukvić, V., Šalinović, A. \& Plantak, M.: Springs: DNA barcoding of caddisflies (Insecta, Trichoptera) in Croatia with notes on taxonomy and conservation biology. Nat. Croat., Vol 29, No. 1, 73-98, 2020, Zagreb.

The paper provides the results of DNA barcoding based on the cytochrome c oxidase subunit 1 mitochondrial gene (mtCOI) of 110 Trichoptera specimens collected in 36 springs in the PannonianPeripannonian, central mountainous and Mediterranean part of Croatia. We barcoded 70 species from 32 genera and 15 families. The data obtained show interesting faunistic and taxonomic results, for, for example, the species Rhyacophila cabrankensis, R. balcanica, Crunoecia kempnyi, Allogmaus auricollis and emphasize the need for further faunistic research into springs, in their role as habitats with a specific and very interesting fauna. The mtCOI DNA barcoding should be included in such research, because it would enable better presentation of the results, especially regarding biodiversity, taxonomy, phylogeny and conservation biology, not just as a segment of a local but also of a global process of understanding biodiversity in a different way. The results of this study show a global need for the protection of springs, because they are specific not only as habitats, but also as localities with an interesting fauna and often endemic species of very limited distribution (for example Rhyacophila cabrankensis).

Key words: upper stream reaches, caddisflies, biodiversity, molecular methods, Rhyacophila cabrakenensis 
Kučinić, M., Ćukušić, A., Žalac, S., Delić, A., Cerjanec, D., Podnar, M., Ćuk, R., Vučković, I., Previšić A., Vuković M., Stanić Koštroman S., Bukvić, V., Šalinović, A. \& Plantak, M.: Izvori: DNA barkodiranje tulara (Insecta, Trichoptera) u Hrvatskoj s napomenama o taksonomiji i konzervacijskoj biologiji. Nat. Croat., Vol 29, No. 1, 73-98, 2020, Zagreb.

U radu se prikazuju rezultati DNA barkodiranja temeljenog na mitohondrijskom genu za podjedinicu 1 citokrom c oksidaze (mtCOI), za 110 primjeraka Trichoptera prikupljenih u 36 izvora u panonsko-peripanonskom, središnje-planinskom i mediteranskom području Hrvatske. DNA barkodirano je 70 vrsta iz 32 roda i 15 porodica. U studiji se ukazuje na neke zanimljive faunističke i taksonomske rezultate, npr. za vrste Rhyacophila cabrankensis, R. balcanica, Crunoecia kempnyi, Allogmaus auricollis te potrebu daljnjih faunističkih istraživanja izvora kao staništa sa specifičnom i vrlo zanimljivom faunom. U ta istraživanja zbog kvalitetnije prezentacije rezultata, posebno u područjima bioraznolikosti, taksonomiji, filogeniji i konzervacijskoj biologiji, potrebno je uključiti i metodu DNA barkodiranja mtCOI, kao segment ne samo lokalnog, nego i globalnog procesa u spoznavanju bioraznolikosti na jedan drugačiji način. Navedeni rezultati ovog rada ukazuju na globalnu potrebu veće zaštite izvora jer su specifični ne samo kao staništa, nego vrlo često i kao područja nalaza endemskih vrsta s vrlo malim područjem rasprostranjenja (npr. Rhyacophila cabrankensis).

Ključne riječi: gornji dijelovi tekućica, tulari, biološka raznolikost, molekularne metode, Rhyacophila cabrankensis

\section{INTRODUCTION}

Springs comprise a particularly interesting type of aquatic habitats characterized by specific hydrological, geological and geomorphological features. They are considered biodiversity hotspots, and also among the most endangered freshwater habitats (KučINIĆ et al., 2015a, 2015b; Pešić et al., 2019; ViteCeK et al., 2015, 2017). Along with biological characteristics of various animal groups, certain spring features are dominant in affecting the composition and structure of their fauna. Type of benthic substrate, spring morphology, water temperature and location of springs (for example springs in forests, springs in open areas) are very important for composition of fauna (Govoni et al. 2018; ILMONEN \& PaAsivirta 2005; Ivković et al., 2013; Kreiling et al., 2020; Matić et al., 2016; Myers \& REsH, 2002). Springs are, in hydrological terms, ' places where subterranean water emerges to the surface' (HABDIJA \& PRIMC, 2019) (Figs 1-4). There are many classifications of springs, and one of them is based on their geomorphological and hydrological characteristics, which have a major effect on spring hydrology, and divides them into limnocrene and rheocrene springs (Habdija \& Primc, 2019; Steinmann, 1907). Limnocrene springs are shaped like lakes of various depths and sizes (Figs 1-2, 4). In contrast, rheocrene springs (Fig. 3) emerge as water flowing to the surface mostly on rocks, thereby creating a waterfall as the initial part of the stream (Habdija \& PRIMC, 2019).

The faunistic uniqueness of springs is also a consequence of their spatial isolation, which can be bigger or smaller, leading to disjunct distributions of populations, which can in time cause allopatric speciation and produce new taxa (subspecies, species) (for example Erman \& Erman, 1995; Marinković Gospodnetić, 1971, 1976, Malicky, 2020, Previšić et al., 2014; Vitecé et al., 2017), by geographic isolation (NeI, 1975). Those characteristics favour many endemic, rare and interesting species belonging to various animal groups, e.g. water mites (for example Pešıć et al., 2019; Pozojević et al., 2020; Di SABAtino et al., 2003), crustaceans (for example GLAzer, 1998; Sidorov et al., 2012, 2018), aquatic insects (for example GrAf et al., 2012; Ivкović et al., 2020; Maiolini et al., 2011; Pollet \& Ivković, 2018; WARInger et al., 2009) and others. There is a great level of endemism in Trichoptera as well, and there are genera and species which can be found only in springs or in upper stream reaches (CIANFICCONI et al., 1998; Hinić et al. 2020; KučInić 
et al. 2015a; Malicky, 2020; Marinković-Gospodnetić 1971, 1976, 1979; OláH, 2010; Previšić et al. 2014a, 2014b; ViTECEK et al. 2015, 2020; WARINGER et al., 2009, 2013, 2015, 2016).

The study of the Earth's biodiversity attained scientific dimensions with the establishment of binomial nomenclature, the taxonomic and basic evolutionary model for the depiction of this diversity (Linnaeus, 1758). Since that period, a large number of organisms have been described, with more than a million known species, which is considered as just a part of total existing biodiversity. Each year thousands of new species within various groups of organisms are described, and the introduction of DNA barcoding based on the cytochrome c oxidase subunit 1 mitochondrial gene (mtCOI), along with the establishment of the Barcode of Life Data Systems (BOLD) (Hebert et al., 2003a, 2003b; RATNASINGHAm \& HeBerT, 2007) resulted in new aspects of global biodiversity on Earth. DNA barcoding has proved to be a useful method in studies of the taxonomy, phylogenesis, phylogeography and biodiversity of different groups of organisms (for example Amora et al. 2015; Brehm et al., 2019; CÁrdenas et al., 2013; De Barros Machado et al., 2017; Dela Cruz et al., 2016; Elías-Gutiérrez et al., 2008; Guo et al., 2016; Huemer et al., 2020; Kučinić et al., 2019a, 2019b; LÉGer et al., 2020; PAuls et al., 2009; SANTOS et al. 2016; Tyagi et al., 2017; Vaglia et al. 2008; Vijayan \& Tsou, 2010; Yang et al., 2015).

Regarding Trichoptera, DNA barcoding has been used in numerous studies in different regions (for example Geraci et al. 2011; HJALmarsson et al., 2018; Morinière et al., 2017; Pauls et al. 2010; VAlladolid et al., 2018, 2019; ZHоu et al., 2016) and that approach has been also applied in Croatia (for example ĆUKUšıć, 2019; ĆuKušıć et al., 2017; Kučınić et al., 2013, 2019a, 2019b; Sziváк et al., 2017).

In this paper we provide (1) an overview of DNA barcoded species of Trichoptera collected in springs in different parts of Croatia, including some literature data (KučINIĆ et al., 2016, 2017, 2019a, Tab. 2); (2) a review of some preliminary taxonomic features; (3) some aspects of threats to the caddisfly spring fauna and their conservation.

This study does not encompass certain genera and species that were found in Croatian springs and are DNA barcoded (for examples Rhyacophila hirticornis McLachlan, 1879, Agapetus sp., Diplectrona sp., Potamophylax sp.), and also does not provide detailed information about trichopteran spring fauna, which are the subject of other scientific studies in progress.

\section{MATERIAL AND METHODS}

\section{Field work}

Collecting of Trichoptera was performed at 36 springs presented in Tab. 1 containing a checklist of all springs with data on spring type (limnocrene- or rheocrene), geocoordinates, biogeographical region, basin and ecoregion. Caddisflies were collected during the night, with small portable batteries and $12 \mathrm{~W}$ UV lamps and during the day by entomological nets. All collected specimens were stored in absolute ethanol.

\section{Biogeographical presentation}

There are three biogeographical divisons of Croatia relevant for this study, and the results are presented according to each of them. BERTić et al. (2001) divide Croatia into three biogeographical regions: the Pannonian-Peripannonian in the north and east, the 
central mountainous in the middle and the Mediterranean in the south (Fig. 5). Nine springs are in the Panonnian-Peripannonian part, fifteen in the central mountainous part and twelve are in the Mediterranean part (Tab. 1, Fig. 5).

All streams in Croatia belong to one of two basins: the Black Sea and the Adriatic Sea Basin (Tab. 1, Primc \& Habdija, 2019; Vilenica et al., 2015). The Black Sea Basin encompasses streams from the Panonnian-Peripannonian and central mountainous parts (21 springs in this paper), and the Adriatic Sea Basin those in the Mediterranean region (15 springs in this paper) (Tab. 1).

In the 1970-ies Illies divided Europe, regarding hydrology and biological freshwater data, into 25 biocenotic ecoregions (Illies, 1978), with Croatia lying in two of them, Dinaric Western Balkans - Ecoregion 5 (ER5) and Hungarian (Pannonian) Lowland Ecoregion 11 (ER11) (Illies, 1978; Graf et al., 2020 - www.freshwater.info). In this study, 34 springs are in Ecoregion 5, and 2 springs in Ecoregion 11 (Tab. 1, Fig. 5).

Karst boundaries are given according to Biondić et al. (2009). There are 30 springs from this study in the karst area (Fig. 5).

\section{Laboratory work}

In order for us to be able to use DNA-based methods of specimen identification along with morphological features, all collected material was preserved in absolute ethanol. The DNA vouchers of the barcoded samples are stored in the Croatian Natural History Museum.

Species identification was done according to Malicky (2004) and KumansKi $(1985,1988)$. Systematics follows Morse (2020). In Tab. 2 there are data concerning determination according to morphological features (first column), specimens ID, Locality/Family, BOLD Sequence ID and species identification after DNA barcoding analyses (last column).

Macrophotographing of Trichoptera adults was carried out using a Leica Wild MZ8 stereomicroscope and Olympus SP-500 UZ digital camera, processed with the computer program Olympus Quick Photo Camera 2.2 at the tree pathology laboratory, Department of Forest Protection and Wildlife Management at the Faculty of Forestry, University of Zagreb.

DNA extraction and PCR amplification. Genomic DNA was extracted from legs of 110 specimens listed in Tab. 2. Genomic DNA was extracted from legs or part of body for small specimens using GenElute Mammalian Genomic DNA Miniprep kit (SigmaAldrich, Germany) according to the manufacturer's specifications and eluted in $50 \mu \mathrm{l}$ of elution buffer. For the amplification of the COI-5P barcode region primers: LCO1490 and HCO2198 (Folmer et al., 1994) were used. For specimens that could not be amplified with Folmer primers, specific primers were designed: TM3 HCOI (TGATTYTTYGGYCACCCWGAAGTTTA), TM4 HCOI (TGATTYTTYGGRCACCCWGAAGTTTA) or a mix of primers C_LepFolF and C_LepFolR was used (HERnÁNDEZ-TriAnA et al., 2014). The volume of mixture for polymerase chain reactions (PCR) was $50 \mu$ l. The PCR mixture contained 1 x Go Taq®Reaction Buffer (containing $1.5 \mathrm{mM} \mathrm{MgCl2}$, Promega), 0.2 $\mathrm{mM}$ of each dNTP, $0.4 \mu \mathrm{M}$ of each primer, 1.25 units of Go Taq®DNA Polymerase (Promega) and $5 \mu \mathrm{l}$ of DNA eluate. PCR cycling conditions comprised an initial denaturation step $\left(94^{\circ} \mathrm{C}\right.$ for $\left.2 \mathrm{~min}\right)$ followed by 35 cycles of denaturation at $94^{\circ} \mathrm{C}$ for $30 \mathrm{~s}$, annealing at $50^{\circ} \mathrm{C}$ for $30 \mathrm{~s}$ and elongation at $72^{\circ} \mathrm{C}$ for $90 \mathrm{~s}$ and a final extension step of $72^{\circ} \mathrm{C}$ for $7 \mathrm{~min}$. Product purification and bidirectional sequencing was performed by 
Macrogen Inc. Sequencing Service (Seoul, South Korea and Macrogen Europe) using the amplification primers. Sequences were edited manually and aligned using the program BioEdit (HALL, 1999). DNA sequences obtained in this study were submitted for phylogenetic analysis of Rhyacophila species to Barcode of Life Data Systems (BOLD, Ratnasingham \& Hebert 2007, Tab. 2). For the 110 DNA barcode sequences obtained in this study, a similarity search was performed using the BOLD Identification Engine (available on http://boldsystems.org/) which uses all sequences uploaded to BOLD from public and private projects to locate the closest match.

DNA data analysis - phylogenetic reconstruction and species delimitation methods. For phylogenetic analysis of Rhyacophila species two different methods of tree reconstruction were used: Neighbor-Joining (NJ) and Maximum likelihood (ML) as implemented in MEGA 7.0. (Kumar et al., 2016) to infer phylogeny-based specimen identifications. Inter- and intraspecific genetic uncorrected pairwise divergences ( $p$ - distances) were calculated in MEGA 7.0. (KumAr et al., 2016). The number of hypothetical species within the data set was estimated based on barcode gap (difference between inter- and intraspecific genetic distances) with the use of Automatic Barcode Gap Discovery, ABGD (Puillandre et al., 2012) (Fig. 10, Appendix 1). DNA barcode sequences were submitted to the ABGD online website and analysed under the following settings: $\mathrm{P}$ (prior intraspecific divergence) set from 0.001 (Pmin) to 0.08 (Pmax) and Steps set to 10; $\mathrm{X}$ (minimum relative gap width) set to 1 ; $\mathrm{Nb}$ bins (for distance distribution) set to 20; we selected the Kimura (K80) model and set TS/TV to 2.0. The data set for phylo-

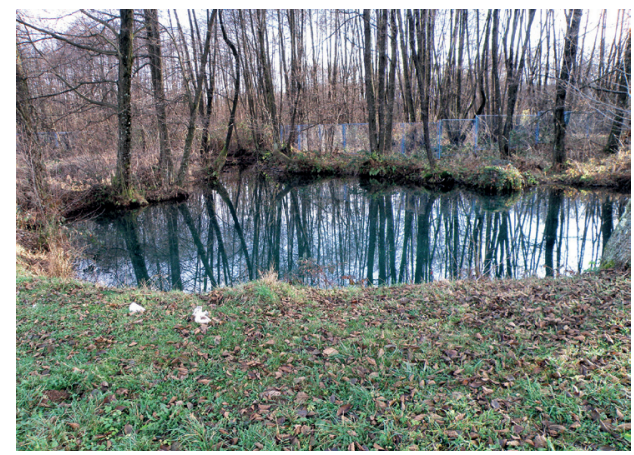

Fig. 1. Pašina vrela spring.

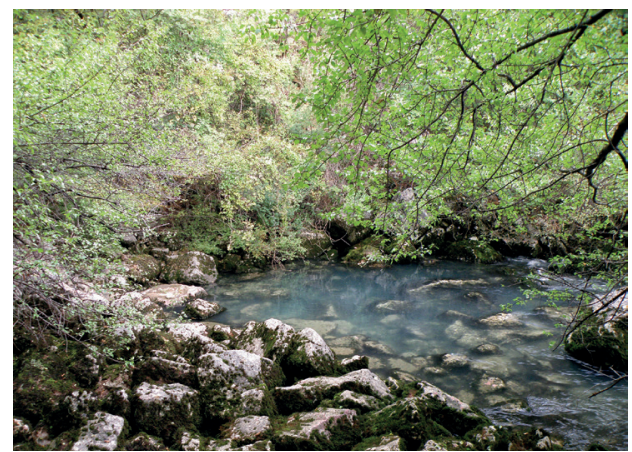

Fig. 3. Spring of the Zrmanja River.

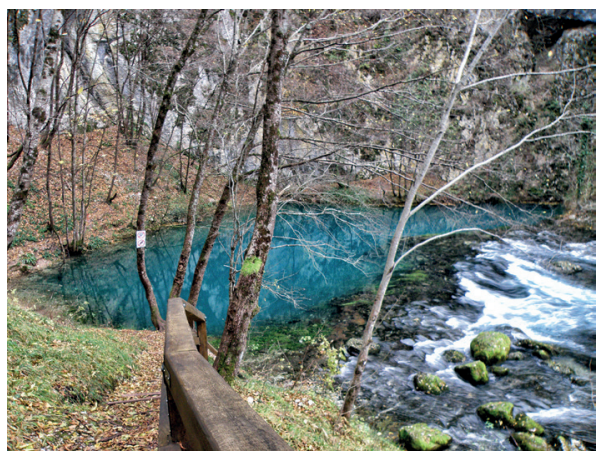

Fig. 2. Spring of the Una River.

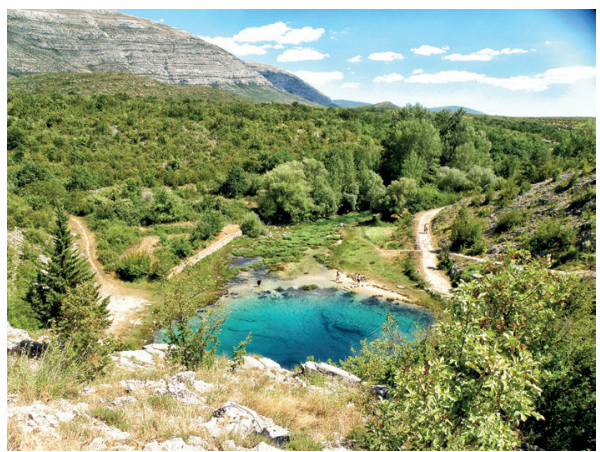

Fig. 4. Glavaš spring of the Cetina River. 
genetic analysis comprised the DNA barcodes amplified from Rhyacophila cabrankensis Malicky, Previšić \& Kučinić, 2007 (TRCAB_1), R. vulgaris Pictet, 1834 (TRVUL) and the outgroup species Anabolia furcata Brauer, 1857 (TAFUR_1), along with all available Rhyacophila barcode sequences retrieved from the Barcode of Life Data Systems (BOLD; Ratnasingham \& Hebert, 2007)

Due to the more detailed presentation of DNA barcoded caddisflies in the springs in this study we included also the DNA barcoding data presented in previous studies (Kučınić et al., 2016, 2017, 2019a, Tab. 2). Additionally, there are some corrections of previous data; Agrypnia varia (Fabricius, 1793) for the Ruda spring (specimen ID TAVAR_2; BOLD Sequence ID CROTR078-19) given in KučINIć et al. (2019a) actually relates to the Grab spring, which is corrected in this paper (Tab. 2), and M. wageneri Malicky, 1971 was not found at the spring Palje in Konavle (Kučinić et al., 2017) but at the spring in Vodovađa village (Tab. 2).

Tab. 1. List of the 36 study springs where caddisflies were collected with basic characteristics: TS (type of spring): L (limnocrene spring), R (rheocrene spring) (according to HabDIJA \& PrImc, 2019); BR (biogeographical regions of Croatia): PP (Pannonian-Peripannonian part), CM (central mountainous part), ME (Mediterranean part) (according to BERTIĆ et al., 2001); EC (ecoregions): EC5 (ecoregion 5), EC 11 (ecoregion 11) (according to Illies, 1978); BA (basin): BS (Black Sea Basin), AS (Adriatic Sea Basin), * closed karstic system, ${ }^{\bullet}-$ anthropogenic influence.

\begin{tabular}{|c|c|c|c|c|c|c|c|}
\hline & Localities & TS & $\mathrm{BR}$ & $\mathrm{EC}$ & $\mathrm{BA}$ & Long & Lat \\
\hline 1. & spring Jankovac (Mt Papuk) & $\mathrm{R}$ & PP & ER11 & BS & 45,51875 & 17,68664 \\
\hline 2. & spring Škodinovac (Mt Papuk) & $\mathrm{R}$ & PP & ER11 & BS & 45,66388 & 17,33289 \\
\hline 3. & spring of the Šumi stream (Mt Ivanšcica) & $\mathrm{R}$ & $\mathrm{PP}$ & ER5 & BS & 46,18884 & 16,15777 \\
\hline 4. & spring of the Križ stream ${ }^{\bullet}$ & $\mathrm{R}$ & $\mathrm{PP}$ & ER5 & BS & 45,4225 & 16,248 \\
\hline 5. & spring Pašina vrela & $\mathrm{L}$ & $\mathrm{PP}$ & ER5 & BS & 45,28936 & 16,42339 \\
\hline 6. & spring Bijele stijene $\bullet^{\bullet}$ & $\mathrm{R}$ & PP & ER5 & BS & 45,42317 & 16,22337 \\
\hline 7. & spring of the Slunjčica River & $\mathrm{L}$ & PP & ER5 & BS & 45,07964 & 15,58925 \\
\hline 8. & spring of the Rudnica River (Ožanići) & $\mathrm{R}$ & PP & ER5 & BS & 45,21457 & 15,39262 \\
\hline 9. & spring of the Tounjčica River & $\mathrm{R}$ & PP & ER5 & BS & 45,24844 & 15,32317 \\
\hline 10. & spring of the Dobra River ${ }^{\bullet}$ & $\mathrm{R}$ & $\mathrm{CM}$ & ER5 & BS & 45,42795 & 14,95681 \\
\hline 11. & spring Zeleni Vir ${ }^{\bullet}$ & $\mathrm{L}$ & $\mathrm{CM}$ & ER5 & BS & 45,42289 & 14,89573 \\
\hline 12. & spring of the Vitunjčica River & $\mathrm{R}$ & $\mathrm{CM}$ & ER5 & BS & 45,29117 & 15,14049 \\
\hline 13. & spring Izvor (Mt Bjelolasica) & $\mathrm{R}$ & $\mathrm{CM}$ & ER5 & BS & 45,2731 & 14,96323 \\
\hline 14. & spring of the Plitvica stream & $\mathrm{R}$ & $\mathrm{CM}$ & ER5 & BS & 44.90137 & 15,57379 \\
\hline 15. & spring of the Napojište stream & $\mathrm{R}$ & $\mathrm{CM}$ & ER5 & BS & 44,82661 & 15,61666 \\
\hline 16. & spring of the Crna Rijeka River & $\mathrm{R}$ & $\mathrm{CM}$ & ER5 & BS & 44,83086 & 15,61343 \\
\hline 17. & spring of the Drakulić River & $\mathrm{R}$ & $\mathrm{CM}$ & ER & BS & 44.78892 & 15,65101 \\
\hline 18. & spring Keljevac & $\mathrm{L}^{\bullet}$ & $\mathrm{CM}$ & ER5 & BS & 44,72094 & 15,7376 \\
\hline 19. & spring of the Una River & $\mathrm{L}$ & $\mathrm{CM}$ & ER5 & BS & 44,39934 & 16,10382 \\
\hline 20. & spring in the Śtirovača ${ }^{\bullet}$ (Mt Velebit) & $\mathrm{R}$ & $\mathrm{CM}$ & ER5 & BS & 44,69808 & 15,04992 \\
\hline 21. & spring of the Cabranka River & $\mathrm{R}$ & $\mathrm{CM}$ & ER5 & BS & 45,60104 & 14,64079 \\
\hline 22. & spring of the Rječina River & $\mathrm{R}$ & $\mathrm{CM}$ & ER5 & AS & 45,42199 & 14,42127 \\
\hline 23. & spring of the Lika River (Mt Velebit) & $\mathrm{R}$ & $\mathrm{CM}$ & ER5 & AS & 44,42618 & 15,541 \\
\hline 24. & spring Majerovo vrilo (Gacka River) & $\mathrm{L}$ & $\mathrm{CM}$ & ER5 & AS & 44,81471 & 15,3588 \\
\hline 25. & spring Bračana (village Mlini) $\bullet^{\bullet}$ & $\mathrm{R}$ & ME & ER5 & AS & 45,45257 & 13,92448 \\
\hline 26. & spring in the village of Marušići & $\mathrm{L}$ & ME & ER5 & AS & 45,42331 & 13,72946 \\
\hline 27 & spring Čerišnjevica & $\mathrm{R}$ & ME & ER5 & AS & 45,281389 & 13,926111 \\
\hline 28 & spring Špilja (Rabac) & $\mathrm{R}$ & ME & ER5 & AS & 45,08494 & 14,13915 \\
\hline 29 & spring Grdak (Raša River) & $\mathrm{L}$ & ME & ER5 & AS & 45,0926 & 14,01831 \\
\hline 30 & spring of the Vrba stream & $\mathrm{R}$ & ME & ER5 & AS & 43,72087 & 16,40175 \\
\hline 31 & spring of the Zrmanja River ${ }^{\bullet}$ & $\mathrm{R}$ & ME & ER5 & AS & 44,20484 & 16,08444 \\
\hline 32 & spring Glavaš (Cetina River) & $\mathrm{L}$ & ME & ER5 & AS & 43,97648 & 16,4302 \\
\hline 33 & spring Nela (Cetina River) ${ }^{\bullet}$ & $\mathrm{R}$ & ME & ER5 & AS & 43,95345 & 16,40573 \\
\hline 34 & spring of the River Rumin & $\mathrm{L}$ & $\mathrm{ME}$ & ER5 & AS & 43,77979 & 16,6566 \\
\hline 35 & spring of the Grab River & $\mathrm{L}$ & ME & ER5 & AS & 43,64099 & 16,76997 \\
\hline 36 & spring in the village of Vodovađa ${ }^{\bullet}$ & $\mathrm{R}$ & ME & ER5 & AS & 42,51763 & 18,42215 \\
\hline
\end{tabular}




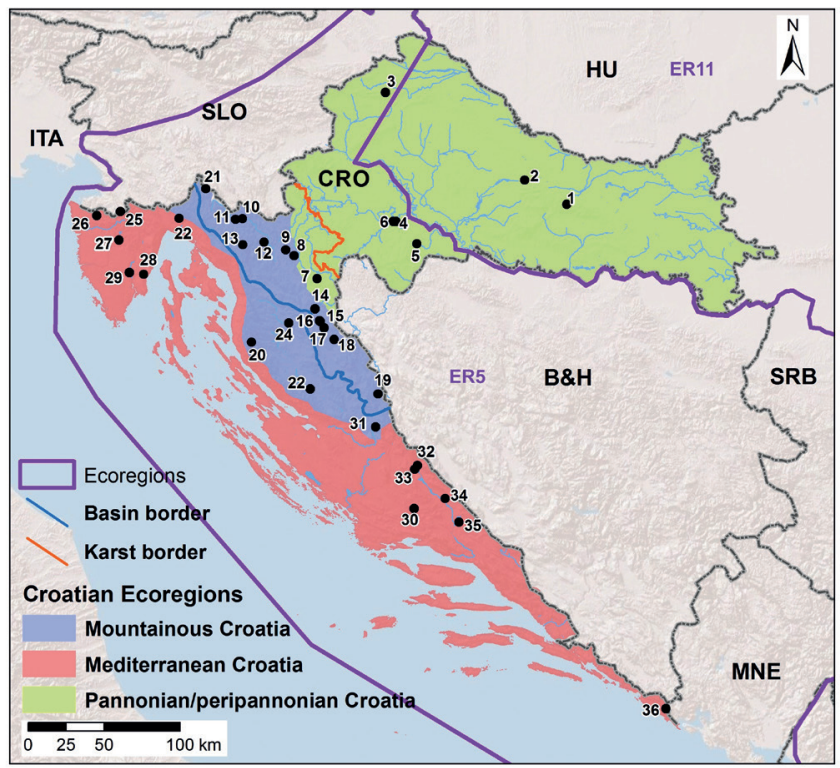

Fig. 5. Map of Croatia showing springs where caddisflies were collected; the numbers correspondns to those in Tab. 1, Ecoregions according to IlLIEs (1978) ER5 - Dinaric Western Balkan, ER11 - Hungarian Lowlands, Basin border divides into the Black Sea Basin (eastern part) and Adriatic Sea Basin (western part).

\section{RESULTS AND DISCUSSION}

A great number of species and specimens were collected in 36 springs in Croatia (Tab. 1) during the last 12 years, and 110 specimens belonging to 70 species, 32 genera and 15 families have been successfully DNA barcoded (Kučınić et al., 2016, 2017, 2019a, Tab. 2). A few of the specimens/species shows genetic variability when compared with data previously entered in the BOLD database (Tab. 2). There is a tendency to establish the smallest value between two different species based on the DNA barcode region (=2\% in Hebert et al., 2003b), but there are no generally accepted values. Within the order Trichoptera intraspecific values range from $0.2 \%$ (GRAF et al., 2015), to $9.4 \%$ (ZHOU et al., 2007). For this type of taxonomical research, in addition to the use of DNA barcoding, it is necessary to make detailed analyses of morphological traits, which generally refers to adults' genitalia for Trichoptera. If possible it is also useful to make analyses of other genes, including nuclear, which generally have a slower evolutionary rate than mitochondrial genes and show less intra- and interspecific genetic divergence values than mitochondrial genes (GERACi et al., 2010; IвRAHImi et al. 2015; JoHANson \& KeijSner, 2008; SAito et al. 2018; WARINGER et al., 2015). The employment of species delimitation bioinformatic tools like ABGD (Puillandre et al., 2012) may also aid in taxonomic decisions (in this study for R. cabrakensis, Fig. 10). Integrative taxonomy represents the basic framework of today's studies of taxonomic features of certain species and groups of organisms (Bilandžija et al., 2013, Previšić et al., 2014; VAlladolid et al., 2018, 2019; ViteceK et al., 2017; YÁnez-Muñoz et al., 2018).

In Tab. 2 we provide a short review of the DNA barcoding results according to the families and species registered in this study and literature data (KučınIć et al., 2016, 
Tab. 2. List of caddisfly species discussed in this study: first column - identification according to morphological features; followed by specimens' ID; Locality/Family; BOLD Sequence ID; last column - DNA species identification with percentage similarity to existing DNA sequences in the BOLD database (identification according to BOLD Identification Engine) $\left({ }^{*}=\right.$ Rhyacophila cabrakenensis, ${ }^{* *}=$ Glosossoma discophorum, ${ }^{* * *}=$ Hydroptila phaon, ${ }^{* * * *}=$ Psychomyia klapaleki, ${ }^{* * * * *}=$ Tinodes antonioi, ${ }^{* * * * * *}=$ Annitella apfelbecki, *******=Drusus croaticus, $* * * * * * * *=$ Micropterna wageneri) (ĆUKUšIć, 2019; KučInIć et al., 2016, 2017); data for the spring Rude (Kučinić et al., 2019a), here corrected as the accurate locality of spring Grab.

\begin{tabular}{|c|c|c|c|c|}
\hline $\begin{array}{l}\text { Species } \\
\text { (morphologically) }\end{array}$ & Specimen ID & Locality & \begin{tabular}{|l|} 
BOLD \\
Sequence ID
\end{tabular} & \begin{tabular}{|l|} 
DNA species \\
identification (BOLD)
\end{tabular} \\
\hline \multicolumn{5}{|c|}{ Family Rhyacophilidae } \\
\hline Rhyacophila balcanica & TRBAL_1 & spring of the Una River & CROTR256-19 & $\begin{array}{l}\text { Rhyacophila balcanica } \\
96.24 \%\end{array}$ \\
\hline $\begin{array}{l}\text { Rhyacophila } \\
\text { cabrankensis }\end{array}$ & TRCAB_1 & spring of the River Čabranka & CROAA089-18 & $\begin{array}{l}\text { Rhyacophila vulgaris } \\
(97.61 \%)^{*}\end{array}$ \\
\hline Rhyacophila dorsalis & TRDOR_2 & spring of the River Cabranka & CROAA060-18 & $\begin{array}{l}\text { Rhyacophila dorsalis } \\
(100 \%)\end{array}$ \\
\hline $\begin{array}{l}\text { Rhyacophila cf. } \\
\text { fasciata }\end{array}$ & TRFAS_1 & spring Zeleni Vir & CROTR264-19 & $\begin{array}{l}\text { Rhyacophila fasciata } \\
(97 \%)\end{array}$ \\
\hline Rhaycophila laevis & TRLAE_1 & spring of the Šumi stream & CROTR266-19 & $\begin{array}{l}\text { Rhacophila laevis } \\
(97.76 \%)\end{array}$ \\
\hline $\begin{array}{l}\text { Rhyacophila } \\
\text { torrentium }\end{array}$ & TRTOR_1 & spring Zeleni Vir & CROAA018-18 & $\begin{array}{l}\text { Rhyacophila torrentium } \\
(99.54 \%)\end{array}$ \\
\hline Rhyacophila tristis & TRTRI_4 & spring in Vodovađa village & CROAA098-18 & $\begin{array}{l}\text { Rhyacophila tristis } \\
(97.15 \%)\end{array}$ \\
\hline Rhyacophila tristis & TRTRI_5 & spring in Vodovađa village & CROTR011-19 & $\begin{array}{l}\text { Rhyacophila tristis } \\
(99.47 \%)\end{array}$ \\
\hline Rhyacophila tristis & TRTRI_7 & spring in Vodovađa village & CROTR031-19 & $\begin{array}{l}\text { Rhyacophila tristis } \\
(97.71 \%)\end{array}$ \\
\hline \multicolumn{5}{|c|}{ Family Glossostomatidae } \\
\hline $\begin{array}{l}\text { Glossosoma } \\
\text { discophorum }\end{array}$ & TGDIS_1 & spring of the River Tounjčica & CROAA004-18 & $\begin{array}{l}\text { Glossosoma neretvae }^{* *} \\
(99.08 \%)\end{array}$ \\
\hline $\begin{array}{l}\text { Glossosoma } \\
\text { discophorum }\end{array}$ & TGDIS_2 & spring of the River Vitunjčica & CROAA035-18 & $\begin{array}{l}\text { Glossosoma neretvae }^{* *} \\
(98.88 \%)\end{array}$ \\
\hline $\begin{array}{l}\text { Glossosoma } \\
\text { discophorum }\end{array}$ & TGDIS_3 & spring of the River Slunjčica & CROAA036-18 & $\begin{array}{l}\text { Glossosoma neretvae }{ }^{* *} \\
(98.88 \%)\end{array}$ \\
\hline $\begin{array}{l}\text { Glossosoma } \\
\text { discophorum }\end{array}$ & TGDIS_4 & spring of the River Una & CROAA037-18 & $\begin{array}{l}\text { Glossosoma neretvae } \\
(98.49 \%)\end{array}$ \\
\hline $\begin{array}{l}\text { Glossosoma } \\
\text { discophorum }\end{array}$ & TGDIS_5 & spring of the River Rumin & CROAA064-18 & $\begin{array}{l}\text { Glossosoma neretvae } \\
(99.54 \%)\end{array}$ \\
\hline $\begin{array}{l}\text { Glossosoma } \\
\text { discophorum }\end{array}$ & TGDIS_6 & spring of the Plitvica stream & CROTR057-19 & $\begin{array}{l}\text { Glossosoma neretvae } \\
(99.67 \% \%)\end{array}$ \\
\hline $\begin{array}{l}\text { Glossosoma } \\
\text { discophorum }\end{array}$ & TGDIS_7 & spring of the River Rumin & CROTR063-19 & $\begin{array}{l}\text { Glossosoma neretvae } \\
(99.84 \%)\end{array}$ \\
\hline $\begin{array}{l}\text { Glossosoma } \\
\text { discophorum }\end{array}$ & TGDIS_8 & spring of the River Grab & CROTR090-19 & $\begin{array}{l}\text { Glossosoma neretvae }^{* *} \\
(100 \%)\end{array}$ \\
\hline \multicolumn{5}{|c|}{ Family Hydroptiliidae } \\
\hline Hydroptila phaon & THPHA_1 & spring Marušići & CROTR232-19 & $\begin{array}{l}\text { Hydroptila occulta } \\
(85.51 \%)\end{array}$ \\
\hline Hydroptila sp. & THYD_5 & $\begin{array}{l}\text { spring of the River Rudnica } \\
\text { (Ožanići) }\end{array}$ & CROTR087-19 & $\begin{array}{l}\text { Hydroptila martini } \\
(100 \%)\end{array}$ \\
\hline Hydroptila sp. & THYD_7 & $\begin{array}{l}\text { spring of the River Rudnica } \\
\text { (Ožanići) }\end{array}$ & CROTR088-19 & $\begin{array}{l}\text { Hydroptila martini } \\
(100 \%)\end{array}$ \\
\hline Hydroptila sp. & THYD_8 & $\begin{array}{l}\text { spring of the River Rudnica } \\
\text { (Ožanići) }\end{array}$ & CROTR141-19 & $\begin{array}{l}\text { Hydroptila martini } \\
(100 \%)\end{array}$ \\
\hline
\end{tabular}




\begin{tabular}{|c|c|c|c|c|}
\hline $\begin{array}{l}\text { Species } \\
\text { (morphologically) }\end{array}$ & Specimen ID & Locality & $\begin{array}{l}\text { BOLD } \\
\text { Sequence ID }\end{array}$ & $\begin{array}{l}\text { DNA species } \\
\text { identification (BOLD) }\end{array}$ \\
\hline Hydroptilidae & THYD_6 & $\begin{array}{l}\text { spring of the River Rudnica } \\
\text { (Ožanići) }\end{array}$ & CROTR139-19 & $\begin{array}{l}\text { Hydroptila tineoides } \\
(100 \%)\end{array}$ \\
\hline Hydroptilidae & THYD_14 & spring Pecki & CROTR251-19 & $\begin{array}{l}\text { Hydroptila lotensis } \\
(99.84 \%)\end{array}$ \\
\hline Hydroptilidae & THTIN_3 & $\begin{array}{l}\text { spring of the River Rudnica } \\
\text { (Ožanići) }\end{array}$ & CROTR102-19 & $\begin{array}{l}\text { Hydroptila } \\
\text { tineoides }(98.54 \%)\end{array}$ \\
\hline \multicolumn{5}{|c|}{ Family Philopotamidae } \\
\hline $\begin{array}{l}\text { Philopotamus } \\
\text { montanus }\end{array}$ & TPMON_2 & spring of the Šumi stream & CROAA130-18 & $\begin{array}{l}\text { Philopotamus montanus } \\
(99.84 \%)\end{array}$ \\
\hline Wormaldia copiosa & TWCOP_2 & spring of the River Čabranka & CROAA044-18 & $\begin{array}{l}\text { Wormaldia copiosa } \\
(99.84 \%)\end{array}$ \\
\hline $\begin{array}{l}\text { Wormaldia } \\
\text { occipitalis }\end{array}$ & TWOCI_4 & spring of the Napojište stream & CROTR068-19 & $\begin{array}{l}\text { Wormaldia occipitalis } \\
(99.20 \%)\end{array}$ \\
\hline $\begin{array}{l}\text { Wormaldia } \\
\text { occipitalis }\end{array}$ & TWOC_3 & spring Škodinovac & CROTR061-19 & $\begin{array}{l}\text { Wormaldia occipitalis } \\
(99.67 \%)\end{array}$ \\
\hline $\begin{array}{l}\text { Wormaldia } \\
\text { occipitalis }\end{array}$ & TWOCI_6 & spring Bijela stijene & CROTR245-19 & $\begin{array}{l}\text { Wormaldia occipitalis } \\
(99.37 \%)\end{array}$ \\
\hline Wormaldia subnigra & TWSUP_2 & spring Cerišnjevica & CROTR099-19 & $\begin{array}{l}\text { Wormaldia subnigra } \\
(99.52 \%)\end{array}$ \\
\hline \multicolumn{5}{|c|}{ Family Polycentropodidae } \\
\hline Cyrnus trimaculatus & TCTRI_6 & spring Cerišnjevica & CROTR217-19 & $\begin{array}{l}\text { Cyrnus trimaculatus } \\
(99.84 \%)\end{array}$ \\
\hline Plectrocnemia brevis & TPBRE_1 & spring of the River Dobra & CROAA071-18 & $\begin{array}{l}\text { Plectrocnemia brevis } \\
(98.39 \%)\end{array}$ \\
\hline $\begin{array}{l}\text { Plectrocnemia } \\
\text { conspersa }\end{array}$ & TPCON_2 & spring Izvor (Bjelolasica Mt) & CROTR008-19 & $\begin{array}{l}\text { Plectrocnemia conspersa } \\
(100 \%)\end{array}$ \\
\hline $\begin{array}{l}\text { Plectrocnemia } \\
\text { conspersa }\end{array}$ & TPCON_4 & spring of the Drakulić River & CROTR076-19 & $\begin{array}{l}\text { Plectrocnemia conspersa } \\
(100 \%)\end{array}$ \\
\hline $\begin{array}{l}\text { Plectrocnemia } \\
\text { conspersa }\end{array}$ & TPCON_5 & spring of the stream Plitvica & CROTR192-19 & $\begin{array}{l}\text { Plectrocnemia conspersa } \\
(99.75 \%)\end{array}$ \\
\hline $\begin{array}{l}\text { Plectrocnemia } \\
\text { conspersa }\end{array}$ & TPCON_6 & spring of the River Dobra & CROTR144-19 & $\begin{array}{l}\text { Plectrocnemia conspersa } \\
(99.83 \%)\end{array}$ \\
\hline $\begin{array}{l}\text { Polycentropus } \\
\text { flavomaculatus }\end{array}$ & TPCON_1 & spring of the River Zrmanja & CROTR272-19 & $\begin{array}{l}\text { Polycentropus } \\
\text { flavomaculatus } \\
(99.67 \%)\end{array}$ \\
\hline Polycentropus sp. & TPLE_1 & spring Bračana (Mlini) & CROTR273-19 & $\begin{array}{l}\text { Polycentropus } \\
\text { flavomaculatus } \\
(99.83 \%) \\
\end{array}$ \\
\hline $\begin{array}{l}\text { Polycentropus } \\
\text { irroratus }\end{array}$ & TPIRR_2 & $\begin{array}{l}\text { spring of the River Rudnica } \\
\text { (Ožanići) }\end{array}$ & CROTR046-19 & \begin{tabular}{|l} 
Polycentropus irroratus \\
$(99.84 \%)$
\end{tabular} \\
\hline \multicolumn{5}{|c|}{ Family Psychomyiidae } \\
\hline Lype cf. reducta & TLRED_3 & spring Cerišnjevica & CROTR081-19 & Lype reducta $(97.97 \%)$ \\
\hline Psychomyia klapaleki & TPKLA_1 & spring of the River Vitunjčica & CROAA038-18 & $\begin{array}{l}\text { Psychomyia morisitai } \\
86.41, \text { Paduniella sp. } \\
86.41^{* * * *}\end{array}$ \\
\hline Tinodes antonioi & TTANT_1 & spring in Marušići village & NIP002-16 & $\begin{array}{l}\text { Tinodes n. sp. nr. } \\
\text { turanicus } 89.1^{* * * * *}\end{array}$ \\
\hline Tinodes sp., female & TTIN_1 & spring in Marušići village & NIP003-16 & $\begin{array}{l}\text { Tinodes n. sp. nr. } \\
\text { turanicus } 89.1^{* * * * *}\end{array}$ \\
\hline Tinodes sp., female & TTIN_2 & spring in Marušići village & NIP004-16 & $\begin{array}{l}\text { Tinodes n. sp. nr. } \\
\text { turanicus } 88.75^{* * * * * *}\end{array}$ \\
\hline Tinodes dives & TTDIV_1 & spring of the River Una & NIP007-16 & Tinodes dives $(98.37 \%)$ \\
\hline
\end{tabular}




\begin{tabular}{|c|c|c|c|c|}
\hline $\begin{array}{l}\text { Species } \\
\text { (morphologically) }\end{array}$ & Specimen ID & Locality & \begin{tabular}{|l} 
BOLD \\
Sequence ID \\
\end{tabular} & $\begin{array}{l}\text { DNA species } \\
\text { identification (BOLD) }\end{array}$ \\
\hline Tinodes pallidulus & TTPAL_1 & spring in Marušići village & CROTR158-19 & $\begin{array}{l}\text { Tinodes pallidulus } \\
(97.82 \%)\end{array}$ \\
\hline Tinodes unicolor & TTUNI_1a & spring Šumi & CROTR204-19 & $\begin{array}{l}\text { Tinodes unicolor } \\
(100 \%)\end{array}$ \\
\hline Tinodes unicolor & TTUNI_2 & spring of the Vrba stream & CROTR205-19 & $\begin{array}{l}\text { Tinodes unicolor } \\
(98.94 \%)\end{array}$ \\
\hline Tinodes unicolor & TTUNI_3 & spring Cerišnjevica & CROTR206-19 & $\begin{array}{l}\text { Tinodes unicolor } \\
(99.82 \%)\end{array}$ \\
\hline Tinodes unicolor & TTUNI_4 & spring Rabac & CROTR089-19 & $\begin{array}{l}\text { Tinodes unicolor } \\
(99.52 \%)\end{array}$ \\
\hline Tinodes waeneri & TTWAE_1 & spring in Marušići village & NIP001-16 & $\begin{array}{l}\text { Tinodes waeneri } \\
(99.69 \%)\end{array}$ \\
\hline \multicolumn{5}{|c|}{ Family Hydropsychidae } \\
\hline $\begin{array}{l}\text { Hydropsyche } \\
\text { instabilis }\end{array}$ & THINS_1 & spring of the River Vitunjčica & CROAA052-18 & $\begin{array}{l}\text { Hydropsyche instabilis } \\
(100 \%)\end{array}$ \\
\hline $\begin{array}{l}\text { Hydropsyche } \\
\text { instabilis }\end{array}$ & THINS_4 & spring of the River Rječina & CROTR201-19 & $\begin{array}{l}\text { Hydropsyche instabilis } \\
(100 \%)\end{array}$ \\
\hline $\begin{array}{l}\text { Hydropsyche } \\
\text { instabilis }\end{array}$ & THINS_5 & spring of the Plitvica stream & CROTR270-19 & $\begin{array}{l}\text { Hydropsyche instabilis } \\
(99.84 \%)\end{array}$ \\
\hline $\begin{array}{l}\text { Hydropsyche } \\
\text { instabilis }\end{array}$ & THINS_6 & spring of the River Grab & CROTR091-19 & $\begin{array}{l}\text { Hydropsyche instabilis } \\
(100 \%)\end{array}$ \\
\hline $\begin{array}{l}\text { Hydropsyche } \\
\text { saxonica }\end{array}$ & THSAX_2 & spring of the Vrba stream & CROTR149-19 & $\begin{array}{l}\text { Hydropsyche saxonica } \\
(100 \%)\end{array}$ \\
\hline \multicolumn{5}{|l|}{ Family Phryganeidae } \\
\hline Agrypnia varia & TAVAR_2 & spring of the River Grab & CROTR078-19 & $\begin{array}{l}\text { Agrypnia varia } \\
(99.84 \%)\end{array}$ \\
\hline Trichostegia minor & TTMIN_1 & spring Majerovo vrilo & CROAA133-18 & $\begin{array}{l}\text { Trichostegia minor } \\
(98.93 \%)\end{array}$ \\
\hline \multicolumn{5}{|l|}{ Family Goeridae } \\
\hline Silo pallipes & TSPAL_1 & spring Bračana (Mlini) & CROTR287-19 & Silo pallipes $(98.83 \%)$ \\
\hline Silo pallipes & TSPAL_3 & spring of the River Slunjčica & CROTR065-19 & Silo pallipes $(98.87 \%)$ \\
\hline \multicolumn{5}{|c|}{ Family Lepidostomatidae } \\
\hline Crunoecia kempnyi & TCKEM_1 & spring of the Napojište stream & CROTR074-19 & $\begin{array}{l}\text { Crunoecia kempeny } \\
(96.67 \%)\end{array}$ \\
\hline Lepidostoma basale & TLBAS_1 & spring Pašina vrela & CROAA024-18 & $\begin{array}{l}\text { Lepidostoma basale } \\
(99.84 \%)\end{array}$ \\
\hline Lepidostoma basale & TLBAS_2 & spring Pašina vrela & CROAA025-18 & $\begin{array}{l}\text { Lepidostoma basale } \\
(99.66 \%)\end{array}$ \\
\hline Lepidostoma basale & TLBAS_3 & spring of the River Grab & CROTR122-19 & $\begin{array}{l}\text { Lepidostoma basale } \\
(99.22 \%)\end{array}$ \\
\hline Lepidostoma hirtum & TLHIT_2 & spring of the River Rudnica & CROTR053-19 & $\begin{array}{l}\text { Lepidostoma hirtum } \\
(100 \%)\end{array}$ \\
\hline \multicolumn{5}{|c|}{ Family Limnephilidae } \\
\hline Allogamus auricollis & TAAUR_1 & spring of the River Una & CROAA040-18 & $\begin{array}{l}\text { Allogamus auricollis } \\
(96.83 \%)\end{array}$ \\
\hline Annitella apfelbecki & TAAPF_1 & spring of the River Zrmanja & CROTR290-19 & $\begin{array}{l}\text { Annitella esparraguera } \\
95.69 \%^{* * * * * *}\end{array}$ \\
\hline Drusus croaticus & TDCRO_1 & spring of the River Vitunjčica & CROAA041-18 & $\begin{array}{l}\text { Drusus monticola } \\
(92.9 \%)^{* * * * * * *}\end{array}$ \\
\hline Drusus croaticus & TDCRO_2 & spring Izvor (Bjelolasica Mt) & CROTR017-19 & $\begin{array}{l}\text { Drusus monticola } \\
(93.69 \%)^{* * * * * * *}\end{array}$ \\
\hline
\end{tabular}




\begin{tabular}{|c|c|c|c|c|}
\hline $\begin{array}{l}\text { Species } \\
\text { (morphologically) }\end{array}$ & Specimen ID & Locality & $\begin{array}{l}\text { BOLD } \\
\text { Sequence ID }\end{array}$ & $\begin{array}{l}\text { DNA species } \\
\text { identification (BOLD) }\end{array}$ \\
\hline Drusus croaticus & TDCRO_3 & spring Majerovo vrilo (River Gacka) & CROTR019-19 & $\begin{array}{l}\text { Drusus monticola } \\
(93.63 \%)^{* * * * * * *}\end{array}$ \\
\hline Drusus croaticus & TDCRO_4 & spring Majerovo vrilo (River Gacka) & CROTR043-19 & $\begin{array}{l}\text { Drusus monticola } \\
(93.43 \%)^{* * * * * * *}\end{array}$ \\
\hline Drusus discolor & TDDIS_1 & spring of the River Čabranka & CROTR020-19 & $\begin{array}{l}\text { Drusus discolor } \\
(98.87 \%)\end{array}$ \\
\hline Drusus schmidi & TDSCH_1 & spring Jankovac & CROAA021-18 & $\begin{array}{l}\text { Drusus schmidi } \\
(100 \%)\end{array}$ \\
\hline Drusus vespertinus & TDVES_1 & spring of the River Una & CROTR275-19 & $\begin{array}{l}\text { Drusus vespertinus } \\
(97.99 \%)\end{array}$ \\
\hline Ecclisopteryx ivkae & TEIVK_1 & spring Glavaš (Cetina river) & CROAA106-18 & $\begin{array}{l}\text { Ecclisopteryx ivkae } \\
(100 \%)\end{array}$ \\
\hline $\begin{array}{l}\text { Glyphotaelius } \\
\text { pellucidus }\end{array}$ & TRBAL_3 & spring Nela (Cetina river) & CROTR064-19 & $\begin{array}{l}\text { Glyphotaelius } \\
\text { pellucidus }(99.36 \%)\end{array}$ \\
\hline $\begin{array}{l}\text { Glyphotaelius } \\
\text { pellucidus }\end{array}$ & TGPEL_4 & spring of the Napojište stream & CROTR069-19 & $\begin{array}{l}\text { Glyphotaelius } \\
\text { pellucidus }(100 \%)\end{array}$ \\
\hline $\begin{array}{l}\text { Glyphotaelius } \\
\text { pellucidus }\end{array}$ & TGPEL_5 & spring Bijela stijena & CROTR227-19 & $\begin{array}{l}\text { Glyphotaelius } \\
\text { pellucidus }(99.22 \%)\end{array}$ \\
\hline Halesus digitatus & THDIG_1 & spring of the River Zrmanja & NIPM009-17 & $\begin{array}{l}\text { Halesus digitatus (100 } \\
\%)\end{array}$ \\
\hline Halesus digitatus & THDIG_2 & spring of the River Rječina & CROTR038-19 & $\begin{array}{l}\text { Halesus digitatus } \\
(99.68 \%)\end{array}$ \\
\hline Halesus digitatus & THDIG_4 & spring of the River Crna rijeka & CROTR221-19 & $\begin{array}{l}\text { Halesus digitatus } \\
(99.84 \%)\end{array}$ \\
\hline $\begin{array}{l}\text { Limnephilus } \\
\text { flavicornis }\end{array}$ & TLFLA_1 & spring Majerovo vrilo & CROTR073-19 & $\begin{array}{l}\text { Limnephilus flavicornis } \\
(99.19 \%)\end{array}$ \\
\hline Limnephilus ignavus & TLING_2 & spring Keljevac & CROTR040-19 & $\begin{array}{l}\text { Limnephilus ignavus } \\
(99.21 \%)\end{array}$ \\
\hline $\begin{array}{l}\text { Limnephilus } \\
\text { hirsutus }\end{array}$ & TLHIR_1 & spring Keljevac & CROTR029-19 & $\begin{array}{l}\text { Limnephilus hirsutus } \\
(99.68 \%)\end{array}$ \\
\hline Limnephilus lunatus & TLLUN_1 & spring Keljevac & CROTR009-19 & $\begin{array}{l}\text { Limnephilus lunatus } \\
(99.51 \%)\end{array}$ \\
\hline Limnephilus lunatus & TLLUN_2 & spring of the stream Plitvica & CROTR071-19 & $\begin{array}{l}\text { Limnephilus lunatus } \\
(100 \%)\end{array}$ \\
\hline Limnephilus lunatus & TLLUN_3 & spring of the River Grab & CROTR233-19 & $\begin{array}{l}\text { Limnephilus lunatus } \\
(99.84 \%)\end{array}$ \\
\hline $\begin{array}{l}\text { Grammotaulius } \\
\text { nigropunctatus }\end{array}$ & TGNIG_2 & spring Grdak (Raša river) & CROTR276-19 & $\begin{array}{l}\text { Limnephilus } \\
\text { marmoratus (98.90\%) }\end{array}$ \\
\hline $\begin{array}{l}\text { Limnephilus } \\
\text { rhombicus }\end{array}$ & TLRHO_2 & spring in the Štirovača (Mt Velebit) & CROTR023-19 & $\begin{array}{l}\text { Limnephilus rhombicus } \\
(99.84 \%)\end{array}$ \\
\hline $\begin{array}{l}\text { Limnephilus } \\
\text { rhombicus }\end{array}$ & TLRHO_5 & spring Majerovo vrilo (Gacka river) & CROTR188-19 & $\begin{array}{l}\text { Limnephilus rhombicus } \\
(99.36 \%)\end{array}$ \\
\hline Limnephilus sparsus & TLSPA_1 & spring of the River Lika (Mt Velebit) & CROTR001-19 & $\begin{array}{l}\text { Limnephilus sparsus } \\
(100 \%)\end{array}$ \\
\hline Limnephilus vittatus & TLVIT_1 & spring Keljevac & CROTR006-19 & $\begin{array}{l}\text { Limnephilus vittatus } \\
(99.84 \%)\end{array}$ \\
\hline Mesophylax aspersus & TMASP_3 & spring Špilja (Rabac) & CROTR083-19 & $\begin{array}{l}\text { Mesophylax aspersus } \\
(99.38 \%)\end{array}$ \\
\hline Mesophylax aspersus & TMASP_4 & spring Špila (Rabac) & CROTR281-19 & $\begin{array}{l}\text { Mesophylax aspersus } \\
(100 \%)\end{array}$ \\
\hline Stenophylax lateralis & TMLAT_1 & spring of the River Lika (Mt Velebit) & CROTR002-19 & $\begin{array}{l}\text { Stenophylax lateralis } \\
(98.46 \%)\end{array}$ \\
\hline
\end{tabular}




\begin{tabular}{|c|c|c|c|c|}
\hline $\begin{array}{l}\text { Species } \\
\text { (morphologically) }\end{array}$ & Specimen ID & Locality & $\begin{array}{l}\text { BOLD } \\
\text { Sequence ID }\end{array}$ & $\begin{array}{l}\text { DNA species } \\
\text { identification (BOLD) }\end{array}$ \\
\hline Stenophylax lateralis & TMLAT_1f & $\begin{array}{l}\text { spring of the River Lika } \\
\text { (Mt Velebit) }\end{array}$ & CROTR154-19 & $\begin{array}{l}\text { Stenophylax lateralis } \\
(100 \%)\end{array}$ \\
\hline $\begin{array}{l}\text { Micropterna } \\
\text { nycterobia }\end{array}$ & TMIC_1 & spring of the River Zrmanja & NIPM003-17 & $\begin{array}{l}\text { Micropterna nycterobia } \\
(98.89 \%)\end{array}$ \\
\hline $\begin{array}{l}\text { Micropterna } \\
\text { nycterobia }\end{array}$ & TMNYC_2 & spring Keljevac & CROTR016-19 & $\begin{array}{l}\text { Micropterna nycterobia } \\
(100 \%)\end{array}$ \\
\hline Micropterna sequax & TMIC_2 & spring of the River Una & NIPM004-17 & $\begin{array}{l}\text { Micropterna sequax } \\
(98.51 \%)\end{array}$ \\
\hline Micropterna testacea & TMTES_3 & spring Majerovo vrilo (River Gacka) & CROTR028-19 & $\begin{array}{l}\text { Micropterna testacea } \\
(100 \%)\end{array}$ \\
\hline $\begin{array}{l}\text { Micropterna } \\
\text { wageneri }\end{array}$ & TPWAG_1 & spring in the village Vodovađa & NIPM002-17 & $\begin{array}{l}\text { Micropterna sequax } \\
(90.38 \%)^{* * * * * * * *}\end{array}$ \\
\hline $\begin{array}{l}\text { Stenophylax } \\
\text { permistus }\end{array}$ & TSPER_1 & spring of the River Una & CROAA065-18 & $\begin{array}{l}\text { Stenophylax permistus } \\
(99.85 \%)\end{array}$ \\
\hline $\begin{array}{l}\text { Stenophylax } \\
\text { permistus }\end{array}$ & TSPER_2 & spring Keljevac & CROTR048-19 & $\begin{array}{l}\text { Stenophylax permistus } \\
(100 \%)\end{array}$ \\
\hline \multicolumn{5}{|c|}{ Family Sericostomatidae } \\
\hline $\begin{array}{l}\text { Sericostoma } \\
\text { flavicorne }\end{array}$ & TSFLA_1 & spring of the River Tounjčica & CROAA062-18 & $\begin{array}{l}\text { Sericostoma flavicorne } \\
(99.72 \%)\end{array}$ \\
\hline \multicolumn{5}{|c|}{ Family Odontoceridae } \\
\hline $\begin{array}{l}\text { Odontocerum } \\
\text { albicorne }\end{array}$ & TOALB_3 & $\begin{array}{l}\text { spring of the River Rudnica } \\
\text { (Ožanići) }\end{array}$ & CROTR047-19 & $\begin{array}{l}\text { Odontocerum albicorne } \\
(97.4 \%)\end{array}$ \\
\hline \multicolumn{5}{|l|}{ Family Beraeidae } \\
\hline Beraea pullata & TBPUL_1 & spring of the Napojište stream & CROTR080-19 & Beraea pullata $(99.84 \%)$ \\
\hline \multicolumn{5}{|l|}{ Family Leptoceridae } \\
\hline $\begin{array}{l}\text { Athripsodes } \\
\text { bilineatus }\end{array}$ & TABIL_1 & spring Pašina vrela & CROAA012-18 & $\begin{array}{l}\text { Atripsodes bilineatus } \\
(100 \%)\end{array}$ \\
\hline Athripsodes cinereus & TACIN_3 & spring of the River Lika (Mt Velebit) & CROTR049-19 & $\begin{array}{l}\text { Athripsodes cinereus } \\
(99.63 \%)\end{array}$ \\
\hline Oecetis notata & TONOT_2 & spring Majerovo vrilo (River Gacka) & CROTR072-19 & Oecetis notata $(99.84 \%)$ \\
\hline Oecetis testacea & TOTES_4 & spring Zeleni vir & CROTR165-19 & $\begin{array}{l}\text { Oecetis testacea } \\
(99.37 \%)\end{array}$ \\
\hline
\end{tabular}

2017, 2019a). We should emphasize that data from the last column ("species identification") in Tab. 2 are not 'stable' and 'constant' and will change when new DNA barcoding data become available, both regarding new localities and species not previously DNA barcoded will be available. For example, five species included in the current study, Rhyacophila cabrankensis Malicky, Previšić \& Kučinić, 2007, Glossosoma discophorum Klapálek, 1902, Hydroptila phaon Malicky, 1976, Psychmia klapaleki Malicky, 1995 and Annitella apfelbecki Klapálek, 1898 were not present in the BOLD database and therefore species identification showed great differences in relation to the nearest species (Tab. 2). The first entries of DNA barcodes of these species into the BOLD database provided the references for reliable species identification for all subsequent specimens belonging to those species (ĆukUšić, 2019; Tab. 2). For example, no data existed previously in the BOLD database for Hydroptila phaon, and our identification was closest to Hydroptila occulta Eaton, 1873 (Tab. 2). Every new entry will therefore ensure a high percentage of identity with $H$. phaon originating from this study (Tab. 2). The same applies to the other four species not present in the BOLD database so far (Tab. 2). 
On the other hand, there are some interesting novelties from the DNA barcoding for eight specimens of Glossosoma discophorum (Fig. 6) found at seven study springs (Tab. 2). This species is distributed in part of SE Europe, i.e. the limnoecoregions ER5, ER6 (Hellenic Western Balkan), ER7 (Eastern Balkan) and ER10 (the Carpathians; GrAF et al., 2020). From the ER5 it was recorded in Bosnia and Herzegovina (Stanić-Koštroman et al., 2015), Montenegro (KRUŠNIK, 1987) and Serbia (ŽIvić et al., 2006), being described at the beginning of the $20^{\text {th }}$ century from central Bosnia (KLAPÁLEK, 1902). However, no data for this species existed in the BOLD database. All our data were grouped together with a high similarity of up to $98.49 \%$ - 100\% (Tab. 2) with Glossosoma neretvae Marinković-Gospodnetić, 1988 which is present in the BOLD database with one, probably misidentified, specimen. According to the research so far, G. neretvae is a microendemic specis of Bosnia and Herzegovina, distributed only in the lower part of the Neretva River (MARINKović-Gospodnetić, 1988; Stanić-Koštroman et al., 2015, M. Kučinić unpublished data). The ongoing study. which includes these two species and DNA barcoded data, shows significant differences in the DNA barcode between G. discophorum and G. neretvae at the level of 'true' species (unpublished data A. Ćukušić, M. Kučinić). Thus all our data in Tab. 2 are related only to Glossosoma discophorum, and not to G. neretvae as matched by the BOLD identification engine (species identification, Tab. 2). This is a very good example of potential consequences of misidentified samples in the BOLD database.

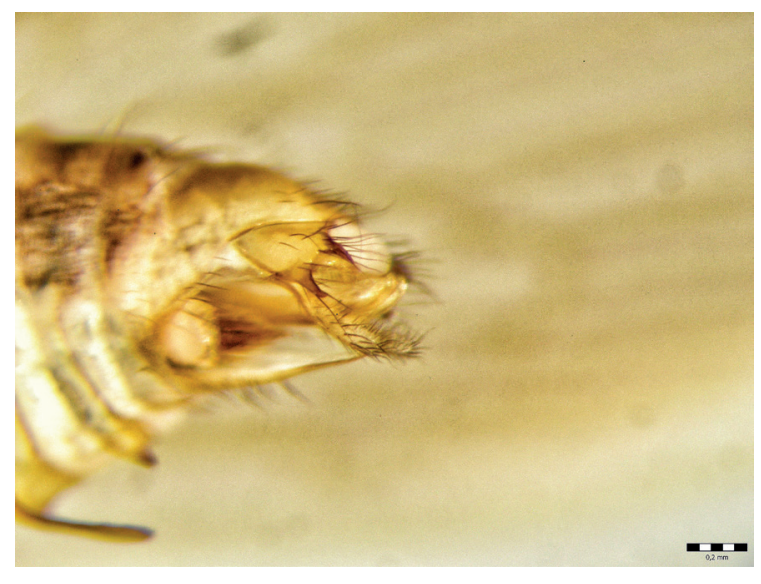

Fig. 6. Glossosoma discophorum Klapálek, 1902. Male genitals, lateral view, collected at the spring of the Una River.

Within the family Rhyacophilidae some species included in the current study show considerable variability of DNA barcoded specimens (Tab. 2). Especially interesting is the endemic species Rhyacophila cabrankensis (Figs 7-8), described on specimens collected from the spring of the Cabranka River (MALICKy et al., 2007). Results of the phylogenetic analysis based on COI show an unresolved pattern of divergence between this species and R. vulgaris Pictet, 1834 (Fig. 9), i.e. they resolved the R. cabrankensis and two lineages of $R$. vulgaris trichotomy (Fig. 10). According to the same phylogenetic tree (Fig. 10), R. simulatrix McLachlan, 1879 is highly supported as a sister taxon to R. cabrankensis and $R$. vulgaris. $P$-distance values supported the presumed close relationship of two species, $R$. cabrankensis and $R$. vulgaris, based on morphology. The value of uncorrected pairwise distance ( $p$-distance) between $R$. vulgaris and $R$. cabrankensis $(1.8 \%)$ is lower than the maximum intraspecific value of $R$. vulgaris (2.3\%) (Tab. 3$)$. In addition, the interspecific genetic distance between $R$. vulgaris and $R$. cabrankensis is 
lower than the intraspecific distance reported in Morinière et al. (2017) within $R$. fasciata $(3.86 \%)$, R. obliterata (3,64\%) and R. vulgaris (3.15\%), which indicates a possibility that $R$. cabrakenensis has subspecies status Nevertheless, in the ABGD analysis (Fig. 10), $R$. cabrankensis formed one group (Group 1), separated from group R. vulgaris (Group 3 and 4 ), which would indicate that $R$. cabrakenensis is a true species.
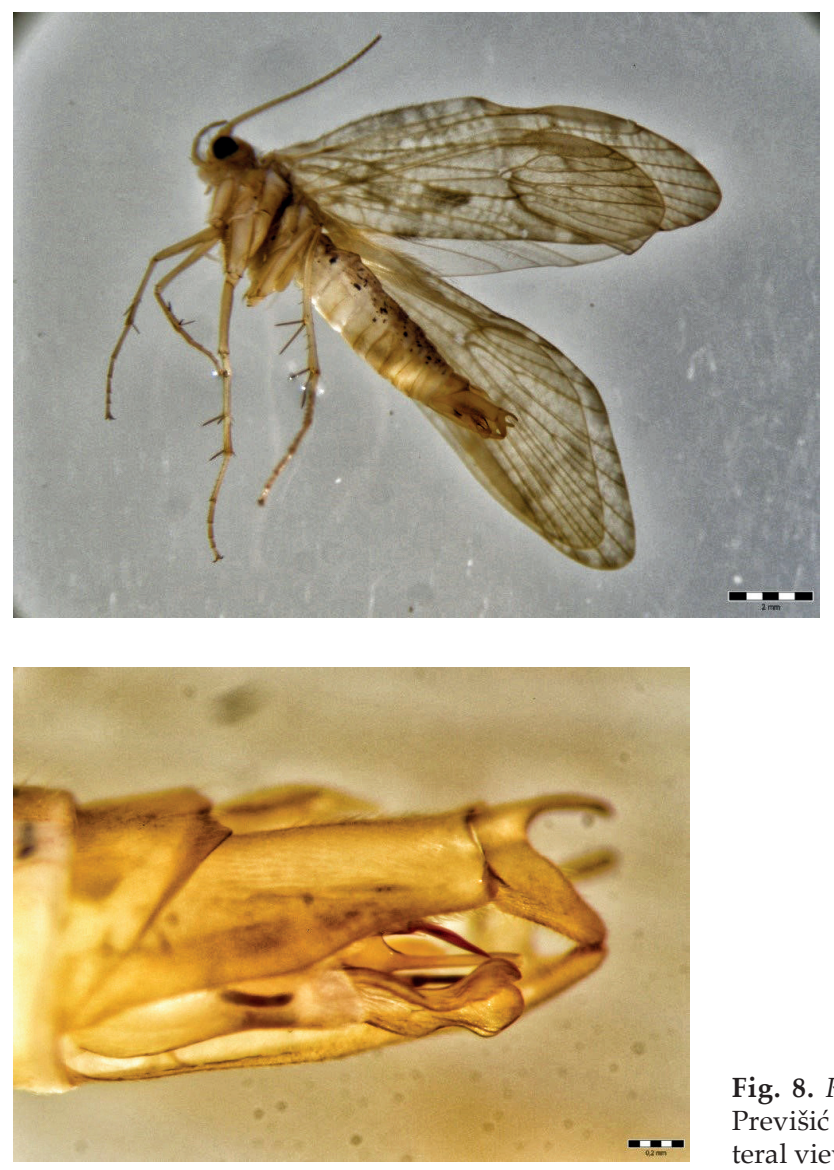

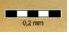

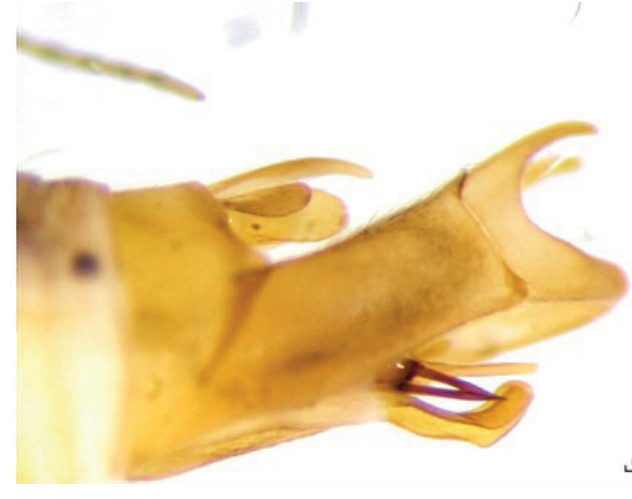
Ćukušić).
Fig. 7. Adult male of Rhycophila cabrankensis Malicky, Previšić \& Kučinić 2007, collected in the spring of the Čabranka River (photo M. Kučinić).

Fig. 8. Rhyacophila cabrankensis Malicky, Previšić \& Kučinić, 2007, male genitalia, lateral view, left side (photo M. Kučinić).

Fig. 9. Rhyacophila vulgaris Pictet, 1834, male genitalia, lateral view, left side (photo A. 


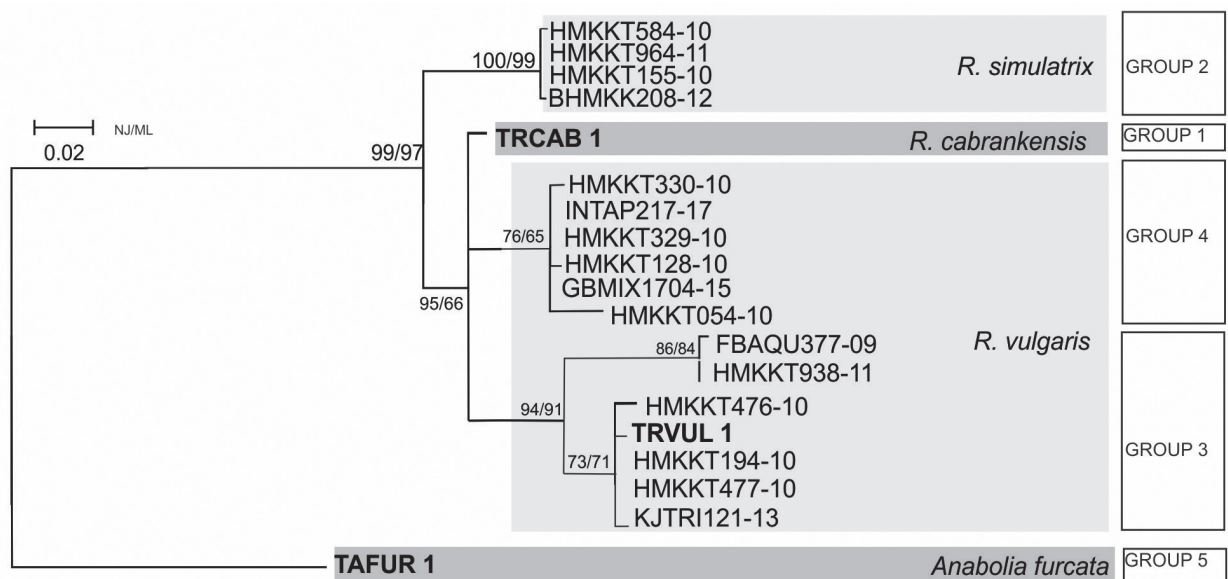

Fig. 10. Maximum likelihood (ML) phylogram based on a $658 \mathrm{bp}$ long fragment of the DNA barcode region showing the relationships between Rhyacophila species. Numbers above the branches represent bootstrap support (BS) for Neighbor-Joining (NJ) and ML analysis (NJ/ML). The groups delineated by the Automatic Barcode Gap Discovery (ABGD) approach are shown on the right side of the tree. Specimen ID from sequences obtained in this study written in bold.

However, two lineages of $R$. vulgaris were also delineated in separate groups by ABGD analysis, which indicates the possibility of there being two species (Fig. 10), even though this is not supported by the morphology (MALICKY, 2004). In order to resolve phylogenetic relationships of these species it is necessary to include additional markers, such as nuclear genes and more specimens. Rhyacophila vulgaris and $R$. cabrankensis are allopatric species. Rhyacophila cabrakenensis is endemic to the central-mountainous part of Croatia (the Gorski kotar region) while R. vulgaris is widespread in Europe (Fig. 11). In Croatia, R. vulgaris was recorded in two localities on Mt Žumberak in the northwest part of the Pannonian-peripannonian region of Croatia (Kučinić et al., 2015a, Fig. 11).

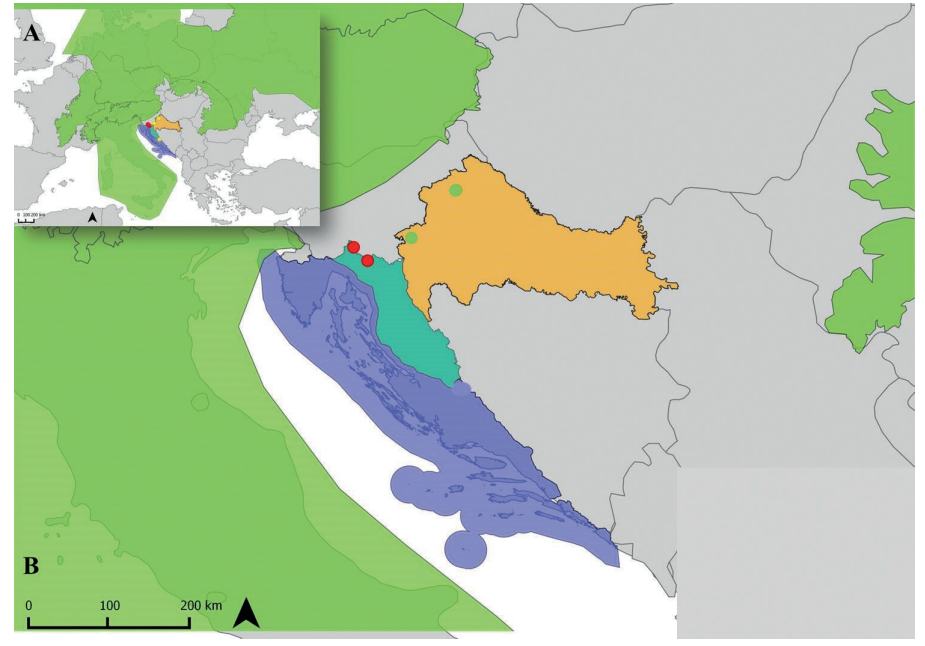

Fig. 11. Records of R. $c a-$ brankensis (red dots) and $R$. vulgaris (green dots) in Croatia with regions according to Bertić et al. (2001) (dark green - mountains, orange - Panonnian-peripanonnian and blue-Mediterranean region) and distribution of $R$. vulgaris in Europe (green field) according to Graf et al. (2020). Fig. B represents the magnified part of Fig. A in the upper left corner. 
Tab. 3. P-distance between. $R$. cabrankensis, $R$. simulatrix, $R$. vulgaris and an outgroup species for the barcode $\mathrm{COI}$ region.

\begin{tabular}{|l|c|c|c|}
\hline Species & R. cabrankensis & R. simulatrix & R. vulgaris \\
\hline R. cabrankensis & - & - & - \\
\hline R. simulatrix & 5.9 & $0-0.3$ & - \\
\hline R. vulgaris & 1.8 & 6.4 & $0-2.3$ \\
\hline Anabolia furcata & 28.5 & 28.9 & 29.4 \\
\hline
\end{tabular}

Within the family Rhyacophilidae there are further examples of relatively high intraspecific $p$-distances observed within DNA barcoded specimens in the current study, i.e. in R. balcanica Radovanović, 1953 (3.78\%), R. laevis Pictet, 1834 (2.4\%) and R. fasciata Hagen, 1859 (3\%). Rhyacophila balcanica can be found mainly in springs and the upper parts of streams and rivers in southeastern Europe (ecoregions ER5, ER6, ER7; MALICKY, 2005; Kučinić et al., 2011; KARAOUZAs et al., 2015; KRUŠNiK, 1987; Radovanović, 1953), and because of its disjunct distribution between different populations we could well expect even higher intraspecific genetic variabilities between various populations. However, no regular or constant morphological differences among adults collected from various localities and populations have been determined. Similar data were obtained from analyses of the larvae collected from the Krka River in Croatia (Karaouzas et al., 2015).

In $R$. fasciata Hagen, 1859, unlike in R. cabrankensis, a significant morphological variability of the male genitalia was noted by MALicky \& SipAHILER (1993) and MALicky (2004) for nominal species and 5 forms (subspecies) distributed in various parts of Europe and Asia (MALICKY, 2004). In more recent research the subspecies (forma) kykladica Malicky \& Sipahiler 1993 from Greece was given species rank (VALLADolid et al., 2019), and similar taxonomic research has been conducted analysing populations from other parts of its distribution range, including Croatia (VALladolid, 2020, in press)).

Rhyacophila tristis Pictet, 1834 was the extensively studied including morphological and genetic analyses; the results showed significant genetic differences between eastern (Carpathians) and western populations (Alps), but with no clear morphological differences (BALint et al., 2011). Three specimens of $R$. tristis collected in the Konavle area in the south-easternmost part of Croatia exhibit intraspecific genetic distances in the range of $0.53 \%-2.85 \%$ (Tab. 2).

In this study, two other interesting species from the family Rhyacophilidae were noted. One is Rhyacophila laevis Pictet, 1834 reported with one DNA barcoded specimen from the spring of Sumi in northwestern Croatia, which is $2.24 \%$ different from the specimen in the BOLD database (Tab. 2). The obtained values from just one DNA barcoded specimen are not enough for any conclusions to be made, but additional genetic and more extensive morphological analyses can be planned; however, we can assume that this is the case of intraspecific genetic variability of the COI genes in $R$. laevis. The record from the spring of Šmi on Mt Ivanščica is the second finding of $R$. laevis in the Pannonian-Peripannonian part of Croatia. So far, this species was reported from the Žumberačka Reka River in the western part of the Pannonian-Peripannonian region of Croatia (Ćuk \& VučKović, 2009) and in the spring of the Dobra River in the central-mountainous part of Croatia (CERJAnec, 2012 Previšić et al., 2012). Another species is Rhyacophila torrentium Pictet, 1834 recorded at the Zeleni Vir spring in the central mountainous part of Croatia. So far, this species was recorded only at the spring 
of the River Kupa in the central-mountainous part of Croatia (VučKović et al., 2011). The specimen from Zeleni Vir spring matches data for $R$. torrentium from other parts of Europe in the BOLD database with high compatibility (99.54\%) (Tab. 2).

Unlike in the mentioned families, higher degrees of genetic variability of the DNA barcoded region of the COI gene were noted in some species from the families Lepidostomatidae, Limnephilidae and Odontoceridae. For instance, a specimen of Crunoecia kempnyi Morton, 1901 from the family Lepitostoatidae collected at the spring of the Napojište stream in Plitvice Lakes National Park (central mountainous part of Croatia) differs considerably from the data contained in the BOLD database by $3.33 \%$ (Tab. 2) however, still indicating the intraspecific variability. Since this is a spring species with disjunct distribution, amore detailed morphological analysis of the population from that locality in Plitvice Lakes National Park and comparison with other populations will be needed in the future. Plitvice Lakes is the only area in Croatia with records of this species, and the closest populations in Bosnia and Herzegovina are located more than $200 \mathrm{~km}$ away (StAnić-Koštroman et al. 2015).

During this research one interesting species, Allogamus auricollis (Pictet, 1834) from the family Limnephilidae was recorded with a higher level of genetic variability (Tab. 2), probably within intraspecific variability. The specimen of this species was collected at the spring of the Una River (Tab. 2) with a compatibility in the COI region of $96.83 \%$ with data from the BOLD database. This species is morphologically very variable (MALICKY, 2004, 2016), and DNA barcoding confirmed its taxonomic affiliation. In this case DNA barcoding once again proved to be a useful tool for the identification of the taxonomic status of morphologically variable or similar species and confirmed the data of the Malicky study from 2016 (MALICKy, 2016). In it, Malicky showed the morphology and distribution of two taxa: A. auricollis auricollis and A. auricolis braueri Kolenati, 1859. The nominal taxa were distributed in Central Europe (western and central Alps) while subspecies braueri is widespread in Europe including the Carpathians, Balkan Peninsula and British Isles (MaLicky 2016). According to these data and DNA barcoding data from the current study, A. auricoliis braueri is probably distributed in Croatia, which should be confirmed in future research. Allogamus auricollis is a rare species of the Croatian fauna and has been found so far only at the springs of the Una and the Dobra rivers in the central-mountainous part of Croatia (CERJAnec, 2012; Previšić et al. 2012).

A faunistically very interesting finding from the family Limnephilidae is Mesophylax aspersus (Rambur, 1842) in the Špilja spring, near the town of Rabac, in the Mediterranean part of Croatia, the second finding for this region (MALICKY, 1979). M. aspersus was recorded for the first time in Croatia at the beginning of the $20^{\text {th }}$ century on the island of Hvar with two collected specimens, deposited in the collection of Pater Gabriel Strobl in the Admont museum in Austria (Kučinić et al., 2019b; MALICKY, 1979). Two DNA barcoded specimens of $M$. aspersus from the Špilja spring are compatible with the data of this species in the BOLD database with the high percentages of $99.38 \%$ and $100 \%$, respectively (Tab. 2). The family Odontoceridae is represented in our fauna with one very common species, Odontocerum albicorne (Scopoli, 1763). One specimen of O. albicorne was collected from the spring of the Rudnica River, showing differences of $2.6 \%$ in the DNA barcoded region, which makes this finding interesting, although we can assume that it is the intraspecific genetic variability of O. albicorne.

All three mentioned species, C. kempnyi, A. auricollis and O. albicorne, should be studied further because of the differences obtained by DNA barcoding, having in mind 
the distribution, morphological and genetic characteristics of various populations of them in Europe.

Specimens within the families Glossosomatidae, Hydroptilidae, Philopotamidae, Polycentropodidae, Psychomyiidae, Hydropsychidae, Phryganeidae, Goeridae, Beraeidae and Leptoceridae that were DNA barcoded in this study indicate no large variabilities in comparison with corresponding species represented in the BOLD database (Tab. 2). In these families, including also the families Rhyacophilidae and Hydroptilidae, the DNA barcoding method has proved to be useful in confirming identifications of similar species (for example Hydropsyche), of small-sized specimens (for example family Hydroptilidae) or of females which could not be identified by morphology (for example genera in the families Hydrosychidae, Hydroptilidae, Psychomyiidae) (MALICKY, 2004) (Tab. 2).

Results from this study, in line with the results from previous faunistic research of Trichoptera in springs, proved to be interesting faunistically, taxonomically, phylogenetically and phylogeographically (for example Cianficconi et al., 1998; IвRAhimi et al., 2015; Kreiling et al., 2020; Kučinić et al., 2011, 2015; Malicky et al., 2007; Pauls et al., 2006, 2009; Pauls et al., 2006; Previšić et al., 2009, 2014; ViteceK et al. 2015, 2017; WARINGER et al., 2013, 2016), and it is to be expected that the research will continue and result in new valuable results.

Springs are globally, and not only in Croatia, subjected to a great deal of anthropogenic influence (for example Kučınić et al., 2015b; Viтесек et al. 2015, 2017) which ranges from low-impact to completely destructive. From the 36 springs included in this research, anthropogenic influence is visible in 13 of them, i.e. in 34\% (Tab. 2). Water protection today is very important but also it is one of the key segments in protecting Earth's biodiversity, with springs having an essential role on the global level. By protecting springs, we protect the best resources of drinking water, and their biodiversity, which is unique in most of its characteristics (e.g. endemic, rare species etc.).

\section{CONCLUSION}

DNA barcoding shows its value in its ability to reveal the species sets of certain areas or habitat types, in this case of springs, by an approach different from the morphological methodology (for example CerJanec, 2012; Kučinić et al., 2011; Previšić et al. 2012; WARINGER et al., 2009), analysing genetic characteristics of each analysed specimen, or species (for example KučınIć et al., 2019a; SzIvÁK et al., 2017). Results obtained by this approach are very interesting either because they differ at the species level in different populations, or because they are a $100 \%$ match with analyzed specimens from different populations. Both examples in their own way show characteristics of the analyzed specimes, populations and species, i.e. the fauna of the particular area. This is the very reason that DNA barcoding of the Croatian fauna will continue in the future. On one hand, a better scientific presentation of the biodiversity is needed, and on the other, we need it to be efficiently protected. DNA barcoding of organisms - here Trichoptera from Croatian springs - is an additional contribution to the knowledge on this aspect of biodiversity, not only locally, but also as a part of global processes (for example Brehm et al., 2019; Dela Cruz et al., 2016; Hebert et al., 2003a, 2003b; Huemer et al., 2020; LÉGER et al., 2020; KuČInić et al., 2013; Morinière et al., 2017; RATNASINGHAM \& Hebert, 2007; SANTos et al. 2016; Tyagi et al., 2017; VAgLiA et al., 2008; YANG et al., 2015; Zhou et al., 2016). 


\section{ACKNOWLEDGMENTS}

This research is a part of the scientific project "DNA barcoding of Croatian faunal biodiversity" (IP-06-2016-9988) funded by the Croatian Science Foundation and financial support of the University of Zagreb. We are very grateful to the Department of Forest Protection and Wildlife Management at the Faculty of Forestry, University of Zagreb for works in his laboratory and two anonymous reviewers.

Received August 20, 2020

\section{REFERENCES}

Amora, G., Hamada, N., Fusari, L. M. \& Andrade-Souza, V., 2015: An Asiatic Chironomid in Brazil: morphology, DNA barcode and bionomics. ZooKeys 514, 129-144. doi: 10.3897/zookeys.514.9925

Balint, M., Ujvárosi, L., Dénes, A. L. \& Popescu, O., 2011: European phylogeography of Rhyacophila tristis Pictet (Trichoptera: Rhyacophilidae): preliminary results. Zoosymposia 5, 19-28.

Biondić, R., Biondić, B., Rubinić, J., MeašKi, H., KapelJ, S. \& Tepeš, P., 2009: Ocjena stanja i rizika cjelini podzemnih voda na krškom području u Republici Hrvatskoj. Sveučilište u Zagrebu, Geotehnički fakultet (studija), pp 380, Zagreb.

Bertić, I., Lampek Pavčnik, I. \& Radovinović, R., 2001: Republika Hrvatska-Prirodna obilježja, stanovništvo i geografske regije. Satelitski Atlas Hrvatske). Naknada Ljevak \& Gis Data, pp 336.

Bilandžija, H., Morton, B., Podnar M. \& Ć́ Etкović, H., 2013: Evolutionary history of relict Congeria (Bivalvia: Dreissenidae): unearthing the subterranean biodiversity of the Dinaric Karst. Frontiers in Zoology 10, 5. http://www.frontiersinzoology.com/content/10/1/5

Botosaneanu L. \& Taticchi-Viganò, M., 1974: Description d'une nouvelle espèce du genre Tinodes (Trichoptera, Psychomyiidae). Boll. Mus. Zool. Univ. Torino, 2, 9-14.

Brehm, G., Murillo-Ramos, L., Sihvonen, P., Hausmann, A., Schmidt, C.B., Öunap, E., Moser, A., Mörtter, R., Bolt, D., Bodner, F., Lindt, A., Parra L.E. \& Wahlberg, N., 2019: New World geometrid moths (Lepidoptera: Geometridae): Molecular phylogeny, biogeography, taxonomic updates and description of 11 new tribes. Arthropod Systematic and Phylogeny 77 (3), 457-486. DOI: 10.26049/ ASP77-3-2019-5

Cárdenas, P., Rapp, H. T., Klitgaard, B. A., Best, M., Thollesson, M. \& Tenda, O. S., 2013: Taxonomy, biogeography and DNA barcodes of Geodia species (Porifera, Demospongiae, Tetractinellida) in theAtlantic boreo-arctic region. Zoological Journal of the Linnean Society 169, 251-311. https://doi. org/10.1111/zoj.12056

CERJANEC, D., 2012: Ekološke i biogeografske značajke tulara (Insecta, Trichoptera) u različitim staništima porječja rijeke Dobre - Ecological and biogeographical features of caddisflies (Insecta, Trichoptera) in different types of habitats in drainage of the Dobra River. PhD Thesis (on Croatian), University of Zagreb, Zagreb, Croatia, 1-139.

Cianficconi, F., Corallini, C. \& Moretti, G. P., 1998: Trichopteran fauna of the Italian springs. In: Studies in crenobiology. The biology of springs and springbrooks Botosaneanu, L. (Ed. Botosaneanu, L.). Backhuys Publishers, Leiden: 125-140.

Curtis, J., 1834: Descriptions of some hitherto nondescript British species of mayflies of anglers. Lond. Edin. Phil Mag 4, 212, 217.

Ćuk, R. \& VučKović, I., 2009: First record of caddisfly Rhyacophila laevis Pictet, 1834 (Insecta: Trichoptera) in Croatia. Natura Croatica 18 (2), 449-453.

ĆuKUšıć, A., 2019: Određivanje bioraznolikosti faune tulara (Insecta, Trichoptera) u Hrvatskoj metodom barkodiranja [Determination of caddisflies (Insecta, Trichoptera) fauna biodiversity in Croatia using the method of DNA barcoding]. Doktorski rad (in Croatian), Prirodoslovno-matematčki fakultete, Sveučilište u Zagrebu, 1-310.

Ćukušić, A., ĆUK, R., Previšıć, A., Podnar, M., Delić, A., Kučinić, M., 2017: DNA barcoding and first records of two rare Adicella species (Trichoptera: Leptoceridae) in Croatia. Biologia (Slovakia) 72(7), 796-806.

Dela Cruz, J. N. B., Nuñeza, O. M. \& Lin, C-P., 2016: Description of a new Oriental stonefly species, Phanoperla constanspina (Plecoptera: Perlidae) from Mindanao, Philippines and association of life stages using DNA barcoding . Zootaxa 4193 (1), 102-116. 
De Barros Machado, Ishizuka, T. K., de Freitas, P. D., Valiati, V. H. Galetti Jr., P. M., 2017: DNA barcoding reveals taxonomic uncertainty Salminus (Characiformes). Systematics and Biodiversity $\mathbf{1 5}$ (4), 372-382.

Di Sabatino, A., Cicolani, B. \& Gerecke, R., 2003: Biodiversity and distribution of water mites (Acari, Hydrachnidia) in spring habitats. Freshwater Biology 48, 2163-2173. https://doi. org/10.1046/j.1365-2427.2003.01151.x

Eaton, A. E., 1873: On the Hydroptilidae, a family of the Trichoptera. Trans. Ent. Soc. Lond., pp 125-151.

Elías-Gutiérrez, M., Jerónimo, F.M., Ivanova, N.V., Valdez-Moreno, M. \& Hebert, P.D.N., 2008: DNA barcodes for Cladocera and Copepoda from Mexico and Guatemala, highlights and new discoveries. Zootaxa 1839, 1-42.

Erman, N. A. \& Erman, D. C., 1995: Spring permanence, Trichoptera species richness, and the role of drought. Journal oft he Kansas Entomological Society 68 (2), 50-64.

FABRIcius, J.C., 1793: Entomologia systematica emendata et aucta. Secundum classes, ordines, genera, species adjectis synonimis, locis, observationibus, descriptionibus (Tomus II). Impensis Christ. Gottl. Proft, Hafniae, 519 pp.

Geraci, C. J., Zhou, X., Morse, J. C. \& KJer, M., 2010: Defining the genus Hydropsyche (Trichoptera: Hydropsychidae) based on DNA and morphological evidence. Journal of the North American Benthological Society 29 (3), 918-933.

Geraci, C. J., Al-Saffar, M. A., \& Zhou, X., 2011: DNA barcoding facilitates description of unknown faunas: a case study on Trichoptera in the headwaters of the Tigris River, Iraq. Journal of the North American Benthological Society 30 (1), 163-173.

GLAZIER, D.S., 1998: Springs as model systems for ecology and evolutionary biology: a case study of Gammarus minus Say (Amphipoda) in mid-Appalachian springs differing in $\mathrm{pH}$ and ionic content. In: Botosaneanu, L. (Ed.), Studies in crenobiology. Blackhuys Publishers, Leiden: 251-261.

Gmelin, J. F., 1789: Carola a Linné Systema Naturae, Leipzig - G. E. Beer, 1 (3), 1033-1516.

Govoni, D.P., KRISTJÁNsson, B.K. \& Ólafsson, J.S. ,2018: Spring type influences invertebrate communities at cold spring sources. Hydrobiologia 808, 315-325. https://doi.org/10.1007/s10750-017-3434-6

Graf, W., Popijač, A., Previšić, A., Gamboa, M. \& Kučinić, M., 2012: Contribution to the knowledge of Siphonoperla in Europe (Plecoptera: Chloroperlidae): Siphonoperla korab sp. n. Zootaxa 3164, 41-48.

Graf, W., Vitecek, S., Previšić, A. \& Malicky, H., 2015: New species of Limnephilidae (Insecta: Trichoptera) from Europe: Alps and Pyrenees as harbours of unknown biodiversity. Zootaxa 3911 (3), 381-395.

Guo, HF., Guan, B., SHI, FM. \& ZHou, ZJ., 2016: DNA Barcoding of genus Hexacentrus in China reveals cryptic diversity within Hexacentrus japonicus (Orthoptera, Tettigoniidae). ZooKeys 596, 53-63. doi: 10.3897/zookeys.596.8669

Graf, W., Murphy, J., Dahl, J., Zamora-Muňoz, C., López-Rodriguez, M. J. \& Schmid-Kloiber, A., 2020: Dataset "Trichoptera". www.freshwaterecology.info - the taxa and autecology database for freshwater organisms, version 7.0. (access 4 March 2020)

Habdija, I. \& Primc, B., 2019: Limnologija - Ekologija slatkih voda, Alfa, Zagreb, pp 352.

Hagen, H. A., 1859, Die Phryganiden Pictet's. Stettin. ent. Zeit. 20, 153.

HALL, T.A., 1999: BioEdit: a user-friendly biological sequence alignment editor and analysis program for Windows 95/98/NT. Nucl. Acids. Symp. Ser. 41, 95-98.

Hebert, D.N. P., Cywinska, A., Ball, S. L. \& De WAard, J. R. 2003a: Biological identifications through DNA barcodes. Proceedings of the Royal Society B, 270, 313-321. doi: 10.1098/rspb.2002.2218

Hebert, P.D.N., Ratnasingham, S. \& De WaARD, J.R., 2003b: Barcoding animal life: Cytochrome c oxidase subunit 1 divergences among closely related species 2003b: Proceedings of the Royal Society B: Biology letters, 270 (Supp. 1), pp. S96-S99. DOI: 10.1098/rsbl.2003.0025

Hinić, J., Slavevvska-Stamenković, V., Ibrahimi, H., Billali, A., Musliu, M., Kučinić, M., Beerman, A. \& Lesse, F., 2020: The First Record of the Balkan Endemic Caddisfly Drusus osogovicus Kumanski, 1980 (Trichoptera: Limnephilidae) in the Republic of North Macedonia, with DNA barcoding of the species and comments on its ecology and distribution. Acta Zoologica Bulgarica 72 (in press). http://www. acta-zoologica-bulgarica.eu/002358

Hjalmarsson, A.E., Graf, W., Jähnig, S.C. , Vitecek, S. \& Pauls, S.U., 2018: Molecular association and morphological characterisation of Himalopsyche larval types (Trichoptera, Rhyacophilidae). ZooKeys 773, 79-108. doi: 10.3897/zookeys.773.24319

Huemer, P., Karsholt, O., Aarvik, L., Berggren, K., Bidzilya, O., Junnilainen, J., Landry, JF., Mutanen, M., Nupponen, K., Segerer, A., Šumpich, J., Wieser, C., Wiesmair, B., Paul D.N., Hebert, D. N. P., 
2020: DNA barcode library for European Gelechiidae (Lepidoptera) suggests greatly underestimated species diversity. ZooKeys 921, 141-157. doi: 10.3897/zookeys.921.49199

Ibrahimi, H., Kučinić, M., Vitecek, S., Waringer, J., Graf, W., Previšić, A., Bálint, M., Keresztes, L. \& Pauls, S.U., 2015: New records for the Kosovo caddisfly fauna with the description of a new species, Drusus dardanicus sp. nov. (Trichoptera: Limnephilidae). Zotoaxa 4032 (5), 551-568.

Ilmonen, J. \& PAAsivirta, L., 2005: Benthic macrocrustacean and insect assemblages in relation to spring habitat characteristics: Patterns in abundance and diversity. Hydrobiologia, 533, 99-113. Doi: 10.1007/ s10750-004-2399-4

ILlies, J., 1978: Limnofauna Europaea. Gustav Fischer Verlag, Stuttgart and New York, 532 pp.

Ivković, M., MilišA, M., Previšić, A., Popijač, A. \& Mihaljević, Z., 2013: Environmentalcontrol of emergence patterns: Case study of changes in hourly and daily emergence of aquatic insects at constant and variable water temperatures. International Review of Hydrobiology 98, 104-115. doi: 10.1002/ iroh.201301483

Ivković, M., Dorić, V., Baranov, V., Mihaljević, Z., Kolcsár, L-P., Kvifte, G. M., Nerudova, J. \& Pont, C. A., 2020: Checklist of aquatic Diptera (Insecta) of Plitvice Lakes National Park, Croatia, a UNESCO world heritage site. ZooKeys 918, 99-142. doi: 10.3897/zookeys.918.49648

Johanson K. A. \& Keijsner, M., 2008: Phylogeny of the Helicophidae (Trichoptera), with emphasis on the New Caledonian species of Helicopha. Systematic Entomology 33 (3), 451-483.

KLApáleK, F., 1902: Zur Kenntnis der Neuropteroiden von Ungarn, Bosnien und der Hercegovina. Termész. Füzetek 25, 161-180.

Karaouzas, I., Graf, W., Kučinić, M., VučKović, I. \& WARinger, I., 2015: The larva of Rhyacophila balcanica Radovanović, 1953 (Trichoptera: Rhyacophilidae) with notes on ecology. Zootaxa 4057 (3), 444-450.

Kolenati, F., 1859: Jh Maehr Schles Ges p 36, (“1858”).

Kreiling, A. K., Gíslason, G. M. \& Kristjánsson, B. K., 2020: Trichoptera diversity in Icelandic springs. Zoosymposia 18, 46-52.

KRUŠNIK, C., 1987: Trichoptera (Insecta). Fauna Durmitora 2, 201-224.

Kučinić, M., VučKović, I., KutnjaK, H., ŠErić Jelaska, L. \& Marguš, D., 2011: Diversity, distribution, ecology and biogeography of caddisflies (Insecta: Trichoptera) in the Krka River (National Park "Krka", Croatia). Zoosymposia 5, 255-268.

Kučinić, M., Szivák, I., Pauls, S.U., Bálint, M., Delić, A. \& Vučković, I., 2013: Chaetopteryx bucari sp. n., a new species from the Chaetopteryx rugulosa group from Croatia (Insecta, Trichoptera, Limnephilidae) with molecular, taxonomic and ecological notes on the group. ZooKeys 320, 1-28. doi: 10.3897/zookeys.320.4565

Kučinić, M., Cerjanec, D., Vučković, I., Mihoci, I., Perović, F., Kutnjak, H., Ibrahimi, H., Pelić Fixa, D., Žalac, S., Mrnjavčić Vojvoda, A. \& Plantak, M., 2015a: Some new and interesting species of caddisflies (Insecta, Trichoptera) found in Croatia. Natura Croatica 24 (2), 293-310.

Kučinić, M., Previšić, A., Graf, W., Mihoci, I., Šoufek, M., Stanić-Koštroman S., Lelo, S., Vitecek \& WARINGER, J., 2015b: Larval description of Drusus bosnicus Klapálek 1899 (Trichoptera: Limnephilidae) with distributional molecular and ecological features. Zootaxa 3957 (1), 85-97.

Kučinić, M., Ćukušić, A., Podnar, M., Landeka, M., Plavec, H., Plantak, M., Akimbekova, N., \& Žalac, S., 2016: The first record of Tinodes antonioi Botosaneanu \& Taticchi-Viganò, 1974 (Insecta, Trichoptera) in Croatia with DNA barcoding and ecologfical dana and notice of biodiversity and distribution oft he genus Tinodes in Croatia. Natura Croatica 25 (1), 131-149.

Kučinić, M., Ćukušić, A., Žalac, S., Podnar, M., Kambarovich Акhmetov, K., Akimbekova, N., Moldazhanovna Zhumadina, S. \& VučKović, I., 2017: First DNA barcoding and new records of the Mediterranean caddisfly species Micropterna wageneri Mal. (Trichoptera, Limnephilidae) in Croatia with note on DNA barcoding and diversity of genus Micropterna in Croatia. Natura Croatica 26 (1), 81-98.

Kučinić, M., Ćukušić, A., Cerjanec, D., Podnar, M., Plantak, M., Žalac, S., Ćuk, R., Vučković, I., IbraHImi, H. \& Delić, A., 2019a: DNA barcoding of the family Phryganeidae (Insecta, Trichoptera) in Croatia with particular reference to phylogeny, distribution and conservation biology. Natura Croatica 28 (2), 305-323.

Kučinić, M., Ćukušić, A., Plavec, H., Landeka, M., Plantak, M., Vuković, M., Bukvić, V., Franjević, M., ŽAlaC, S. \& LukAč, G., 2019b: Caddisfly fauna characteristics (Insecta, Trichoptera) of four Adriatic islands with a note on DNA barcoding. Natura Croatica 28 (2), 403-413.

Kumanski, K.P., 1985: Trichoptera, Annulipalpia. Fauna Bulgarica 15, 1-244.

Kumanski, K.P., 1988: Trichoptera, Integripalpia. Fauna Bulgarica 19, 1-354. 
Kumar, S., Stecher, G., \& Tamura, K., 2016: MEGA7: Molecular Evolutionary Genetics Analysis version 7.0 for bigger datasets. Mol. Biol. Evol. 33 (7), 1870-1874.

Léger, T., Kehlmaier, C., Charles S. Vairappan, S. C. \& Nuss, M., 2020: Twenty-six new species of Hoploscopa (Lepidoptera, Crambidae) from South-East Asia revealed by morphology and DNA barcoding. ZooKeys 907, 1-99. doi: 10.3897/zookeys.907.36563

LinNaEus, C., 1758: Systema naturae per regna tria naturae: secundum classes, ordines, genera, species, cum characteribus, differentiis, synonymis, locis (in Latin) (10th ed.). Stockholm: Laurentius Salvius.

Maiolini, B., Carolli, M. \& Silveri, L., 2011: Ephemeroptera, Plecoptera and Trichoptera in springs in Trentino (south-eastern Alps Journal of Limnology 70 (Suppl. 1), 122-133. DOI: 10.3274/JL11-70-S1-09

Malicky, H., 1971: Eine neue Micropterna (Trichoptera, Limnephilidae) aus Italien - mit einem überblick über die Gattungen Stenophylax, Micropterna und Mesophylax? Die Höhle (Wien) 22 (1), 15-19.

MaLICKY, H., 1976 (“1975”): Beschreibung von 22 neuen westpaläarktischen Köcherfliegen (Trichoptera). Zeitschrift der Arbeitsgemeinschaft Österreichischer Entomologen 27(3/4), 93, pl. 2 f. 6-8.

MaLIcKY, H., 1979: Revision der Köcherfliegensammlung von Pater Gabriel Strobl im Naturhistorischen Museum Admont (Insecta, Trichoptera). Mitt. Abt. Zool. Landesmus. Joanneum (Graz) 8, 11-42.

Malicky, H., 1995: Eine neue Psychomyia aus dem südöstlichen Mitteleuropa, mit Bemerkungen über die Gattung Metalype (Trichoptera: Psychomyiidae). - Entomologische Zeitschrift (Essen) 105, 441 446. - pogledati

Malicky, H., 2004: Atlas of European Trichoptera. Springer, Dordrecht, pp 384.

MalıcкY, H., 2005: Die Köcherfliegen Griechenlands. Denisia 17, 1-240.

MaLicky, H., 2016: Die mitteleuropäische Verbreitung zweier Morphotypen von Allogamus auricollis (Trichoptera, Limnephilidae), mit phänologischen und bionomischen Notizen. Braueria 16, 29-38.

Malicky, H., 2020: Ein neuer Drusus (Trichoptera, Limnephilidae) aus dem Piemont: Drusus delmastroi n.sp. Braueria 47:38.

Malicky, H. \& Sipahiler, F., 1993: Köcherfliegen (Trichoptera) aus der túrkei, mit Bemerkungen zu weiteren mediterranean Köcherfliegen. Bulletin de la société entomologique Suisse 66, 457-468

Malicky, H., Previšı́, A. \& Kučinić, M., 2007: Rhyacophila cabrankensis nov. spec, from Croatia. Braueria 34,14 .

Malicky, H. \& Sipahiler, F., 1993: Köcherfliegen (Trichoptera) aus der túrkei, mit Bemerkungen zu weiteren mediterranean Köcherfliegen. Bulletin de la société entomologique Suisse 66, 457-468.

Marinković-Gospodnetić, M., 1971: The species of the genus Drusus in Yugoslavia. Godišnjak Biološkog Instituta Univerziteta Sarajevo (Annual of the Institute of Biology, University of Sarajevo) 24, 105-109.

Marinković-Gospodnetić, M., 1976: The differentiation of Drusus species of the group bosnicus. In: MALICKY, H. (Ed.), Proceedings of the First International Symposium on Trichoptera, Dr. W. Junk Publishers, The Hague, Netherland, pp 77-85 pp.

Marinković-Gospodnetić, M., 1979: Trichoptera (Insecta) velikih karstnih izvora u Dinaridima. Drugi Kongres Ekologa. In: Rauš, Đ. (Ed.), Drugi kongres Ekologa Jugoslavije (Second Congress of Ecologists of Yugoslavia). Savez društava ekologa Jugoslavije. Zagreb, pp 1837-1849.

Marinković-Gospodnetić, M., 1988: Dve nove vrste Glossosoma (Trichoptera, Insecta) u Jugoslaviji. Godišnjak Biološkog Instituta 41, 41-47.

Matić, N., Maldini, K., Tomas, D., Ćuk, R., Milović, S, Miklavčić, I. \& Širac, S., 2016: Geochemical characteristics of the Gacka River karstic springs (Dinaric karst, Croatia) with macroinvertebrate assemblages overview. Environmental Earth Sciences 75 (19), 1-19. DOI:10.1007/s12665-016-6087-2

McLachlan, R., 1875 (1874-1880): A Monographic Revision and Synopsis of the Trichoptera of the European Fauna. London \& Berlin, p 139-140, pl. 15, f. 1-6. p 464-465, pl 49 f 1, p 453-454, pl 48 f.

Myers, M.J. \& RESH, V.H., 2002: Trichoptera and other macroinvertebrates in springs of the Great Basin: Species composition, richness, and distribution. Western North American Naturalist 62, 1-13.

Morinière, J., Hendrich L., Balke, M., Beermann A.J., König, T., Hess, M., Koch, S., Müller, R., Leese, F., Hebert, P.D.N., Hausmann, A., Schubart, C.D. \& Haszrrunar, G., 2017: A DNA barcode library for Germanys mayflies, stoneflies and caddisflies (Ephemeroptera, Plecoptera and Trichoptera). Molecular Ecology Resources 17, 1293-1307. DOI: 10.1111/1755-0998.12683

MoRTon, K. J., 1901: Trichoptera, Neuroptera-Planipennia, Odonata, and Rhopalocera collected in Norway in the summer of 1900 . The Entomologist's monthly magazine 37: 69-71, f 1-3

Morse, J.C., 2020: Trichoptera World Checklist. http://entweb.clemson.edu/database/trichopt/index.htm (access 4 August 2020) 
NeI, M., 1975: Molecular Population Genetics and Evolution. North-Holland Research Monographs. Fronitiers of Biology, Vol. 40, Amsterdam, Oxford, pp 288.

OlÁH, J., 2010: New species and new records of Palaearctic Trichoptera in the material of the Hungarian Natural History Museum. Annales historico-naturales Musei nationalis hungarici, 102, 65-117.

Pauls, S. U., Lumbsch , H. T. \& HaAse , P., 2006: Phylogeography of the montane caddisfly Drusus discolor: evidence for multiple refugia and periglacial survival. Molecular Ecology 15 (8), 2153-2169.

Pauls, S.U., Theissinger, K., Ujvarosi, L., Balint M. \& HaAse, P., 2009: Patterns of population structure in two closely related, partially sympatric caddisflies in Eastern Europe: Historic introgression, limited dispersal, and cryptic diversity. Journal of the North American Benthological Society 28 (3), $517-$ 536. DOI: 10.1899/08-100.1

Pauls, S.U., Blahnik, R.J., Zhou, X., Wardwell, C.T. \& Holzenthal, R.W., 2010: DNA barcode dana confirm new species and reveal cryptic diversity in Chilean Smicridea (Smicridea) (Trichoptera: Hydropsychidae). Journal of the North American Benthological Society 29 (3), 1058-1074. doi: 10.1899/09108.1

Pešić, V., Savić, A., JabŁońska, A, Michoński, G., Grabowski, M., Bańkowska, A \& Zawal, A., 2019: Environmental factors affecting water mite assemblages along eucrenon-hypocrenon gradients in Mediterranean karstic springs. Experimental and Applied Acarology 77 (4), 471-486. . doi: 10.1007/ s10493-019-00360-w

Pictet, F. J., 1834: Recherches pour Servír à l'histoire et à l'Anatomie des phryganides. A. Cherbuliez, Geneva. p 182-184, pl 1 f 5a-f, pl 4 f 16-30, pl 15 f 1a-f, in part; p 187, pl 16 f 5; p 141-142, pl 8 f 1 a-f)

Pollet, M. \& Ivković, M., 2018: Dolichopodidae of riverbeds and springs in Croatia with an updated checklist of Croatia (Diptera). Zootaxa 4455 (3), 401-428. DOI:10.11646/zootaxa.4455.3.1

Pozojević, I., Pešić, V., Goldschmidt, T. \& Gottstein, S., 2020: Crenal Habitats: Sources of Water Mite (Acari: Hydrachnidia) Diversity. Diversity 12, 316. https://www.mdpi.com/1424-2818/12/9/316

Previšić, A., Walton, C., Kučinić, M., Mitrikeski, P. T. \& M. Kerovec, 2009: Pleistocene divergence of Dinaric Drusus endemics (Trichoptera, Limnephilidae) in multiple refugia within the Balkan Peninsula. Molecular Ecology 18 (4), 634-647.

Previšić, A., Cerjanec, D., Graf, W. \& Kučinić, M., 2012: Drusus chrysotus (Rambur, 1842) (Trichoptera: Limnephilidae: Drusinae): a new caddisfly species in the Croatian fauna. Natura Croatica 21 (2), 419-425.

Previšić, A., Graf, W., Vitecek, S., Kučinić, M., Bálint, M., Keresztes, L., Pauls S. U. \& Waringer, J., 2014: Cryptic diversity of caddisflies in the Balkans: the curious case of Ecclisopteryx species (Trichoptera: Limnephilidae). Arthropod Systematics and Phylogeny 72 (3), 309-329.

Puillandre, N., Lambert, A., Brouillet, S. \& Achaz, G., 2012: ABGD, Automatic Barcode Gap Discovery for primary species delimitation. Molecuar Ecolology 21 (8), 1864-1877.

Radovanović, M., 1953: Prilog poznavanju Trichoptera Balkanskog poluostrva, prvenstveno u pećinama i planinskim jezerima. Glas SAN, Odeljenje prirodno-matematičkih nauka 7, 11-38.

RAMBUR, J.P., 1842: Histoire naturelle des lnsectes Nêvroptàres, pp 475, 480.

Ratnasingham, S. \& Hebert, P.D.N., 2007: BOLD: The Barcode of Life Data System (www.barcoding life. org. Molecular Ecology Notes 7(3), 355-364. doi: 10.1111/j.1471-8286.2007.01678.x

Saito, R., Kato, S., Kuranishi, R. B., Nozaki, T., Fujino, T. \& Tojo, K., 2018: Phylogeographic analyses of the Stenopsyche caddisflies (Trichoptera: Stenopsychidae) of the Asian Region. Freshwater Science 37 (3), 562-572.

Santos, A.P.M., Nessimian, J.L. \& TakiYa, D.M., 2016: Revised classification and evolution of leucotrichiine microcaddisflies (Trichoptera: Hydroptilidae) based on morphological and molecular. Systematic Entomology 41, 458-480. DOI: 10.1111/syen.12168

Scopoli, J. A., 1763: Entomologia Carniolica exhibens insecta Carnioliæ indigena et distributa in ordines, genera, species, varietates. Methodo Linnæana, Vindobonae, Trattner. - pp. 1: 265.

Sidorov, D. \& Palatov, D., 2012: Taxonomy of the spring dwelling amphipod Synurella ambulans (Crustacea: Crangonyctidae) in West Russia: with notes on its distribution and ecology. European Journal of Taxonomy 23, 1-19. http://dx.doi.org/10.5852/ejt.2012.23.

Sidorov, D., Hou, Z. \& SKet, B., 2018: Three new remarkable amphipod species (Crustacea: Gammaridae) from springs and subterranean waters of Central Asia. Zootaxa 4444 (4), 437-461, DOI:10.11646/zootaxa.4444.4.5

Stanić-Koštroman, S., Previšić, A., A. Planinić, A., Kučinić, M., ŠKobić, D., A. Dedić, A. \& Durbešić, P., 2015: Environmental determinants of contrasting caddisfly (Insecta, Trichoptera) biodiversity in 
the Neretva and Bosna river basins (Bosnia and Herzegovina) under temperate and mediterranean climates. International Review of Hydrobiology 100, 79-95. DOI:10.1002/iroh.201301631

Steinmann, P., 1907. Die Tierwelt der Gebirgsbäche. Eine faunistisch-biologische Studie. (Inauguraldiss.). Brüssel, Verl. F. Vanbuggenhondt.

Szivák, I., Mikes, T., Szalontai, B., Kučinić, M., Vučković, I., Vadkerti, E., Kisfali, P., Pauls, S. U. \& BÁLINT, M., 2017: Ecological divergence of Chaetopteryx rugulosa species complex (Insecta, Trichoptera) linked to climatic niche diversification, Hydrobiologia 794, 31-47. DOI 10.1007/s10750-016-3068-0

Tyagi, K., Kumar, V., Singha, D., Chandra, K., Laskar, B.A., Kundu, S., Chakraborty R. \& Chatterjee, S. A., 2017: Barcoding studies on Thrips in India: Cryptic species and Species complexes. Scientific Reports 7, Article number 4898. https://doi.org/10.1038/s41598-017-05112-7

Vaglia, T., HaXaire, J., Kitching , I. J., MeusnieR, I. \& Rougerie, R., 2008: Morphology and DNA barcoding reveal three cryptic species within the Xylophanes neoptolemus and loelia species-groups (Lepidoptera: Sphingidae). Zootaxa 1923, 18-36.

Valladolid, M., Arauzo, M., Basaguren, A., Dorda, B.A. \& Rey, I., 2018: The Rhyacophila fasciata Group in Western Europe: Confirmation of Rhyacophila denticulata McLachlan 1879 (stat. prom.) and Rhyacophila sociata Navás 1916 (stat. res.), based on morphological and molecular genetic evidence (Trichoptera: Rhyacophilidae), Zootaxa 4418(6), 526-544. https://doi.org/10.11646/zootaxa.4418.6.2

Valladolid, M., Karaouzas, I., Arauzo, M., Dorda, A. B. \& Rey, I., 2019: The Rhyacophila fasciata Group in Greece: Rhyacophila kykladica Malicky \& Sipahiler 1993 (stat. prom.) (Trichoptera: Rhyacophilidae). Morphological description, genetic and ecological features. Zootaxa 4657 (3), 503-522. DOI: http:// dx.doi.org/10.11646/zootaxa.4657.3.5

VIJAYAN, K. \& Tsou, H. C. 2010: DNA barcoding in plants: Taxonomy in a new perspective, Current science 99 (11), 1530-1541.

Vitecek, S., Graf, W., Previšić, A., Kučinić, M., Oláh, J., Bálint, M., Keresztes, L., Pauls, S.U. \& WarinGER, J., 2015: A hairy case: The evolution of filtering carnivorous Drusinae (Limnephilidae, Trichoptera). Molecular Phylogenetic and Evolution 93, 249-260.

Vitecek, S., Kučinić, M., Previšić, A., Živić, I., Stojanović, K., Keresztes, L., Bálint, M., Hoppeler, F., WARINGER, J., GraF, W. \& PAULS, U. S., 2017: Integrative taxonomy by molecular species delimitation : multi-locus data corroborate a new species of Balkan Drusinae microendemics. BMC Evolutionary Biology, DOI 10.1186/s12862-017-0972-5

Vitecek, S., Martini, J., Zittra, C., Kuhlmann, H., Vieira, A. \& Waringer, J., 2020: The larva of Drusus dudor Oláh, 2017, including an updated key to larval Drusinae Banks, 1916 (Insecta, Trichoptera, Limnephilidae). ZooKeys 908, 137-155. doi: 10.3897/zookeys.908.

VučKović, I., Previšić, A. Graf, W \& Kučinić, M., 2011: Description of the female and new data on the distribution of Annitella apfelbecki Klapálek, 1899 (Insecta: Trichoptera). Aquatic Insects 33 (4), 381-389.

Waringer, J., Graf, W., Kučinić, M., Previšsć, A. \& VučKović, I., 2009: The Larva and life cycle of Annitella apfelbecki Klapalek, 1899, including a re-description of Melampophylax nepos McLachlan, 1880 (Trichoptera: Limnephilidae). Aquatic insects 31 (1), 71-80.

Waringer, J., Graf, W., Balint, M., Kučinić, M., Pauls, S.U., Previšić, A., Keresztes, L. \& S. Vitecek, 2013: The larvae of Drusus franzressli Malicky 1974 and Drusus spelaeus (Ulmer 1920) (Trichoptera: Limnephilidae: Drusinae) with notes on ecology and zoogeography. Zootaxa 3637, 1-16.

Waringer, J., Graf, W., Bálint, M., Kučinić, M., Pauls, S.U., Previšić, A., Kereszites, L., Ibrahimi, H., Žıvić, I., BJelanović, K., KrPač, V. \& S. ViteceK, 2015: Larval morphology and phylogenetic position of Drusus balcanicus, D. botosaneanui, D. serbicus and D. tenellus (Trichoptera: Limnephilidae: Drusinae). European Journal of Entomology 112 (3), 344-361.

Waringer, J., Previšić, A., Kučinić, M., Graf, W., Viteceki, S., Keresztes, L., Bálint, M. \& Steffen, U. P. 2016: Larval morphology of the Western Balkans endemic caddisflies Drusus krusniki Malicky 1981, D. vernonensis Malicky 1989, and D. vespertinus Marinković-Gospodnetić 1976 (Trichoptera, Limnephilidae, Drusinae). Zootaxa 4083 (4), 483-500.

www.freshwater.info

YANG, M., ZHAI, Q., YANG, Z. \& ZHANG, Y., 2015: DNA barcoding Satyrine butterflies (Lepidoptera: Nymphalidae) in China. Mithochondrial DNA (Early online) 1-6. DOI: 10.3109/19401736.2015.1038788

Yánez-Muñoz, M. H., Reyes-Puig, C., Reyes-Puig, J.P.,Velasco, J. A., Ayala-Varela, F. \& Torres-CarvaJAL, O., 2018: A new cryptic species of Anolis lizard from northwestern South America (Iguanidae, Dactyloinae). ZooKeys 794, 135-163. doi: 10.3897/zookeys.794.26936 
Zhou, X., KJer, K. \& Morse, J., 2007: Associating larvae and adults of Chinese Hydropsychidae caddisflies (Insecta: Trichoptera) using DNA sekvencas. Journal of the North American Benthological Society 26 (4), 719-742.

Zhou, X., Frandsen, P.B., Holzenthal, R.W, Beet, C.R., Bennett, K.R., Blahnik, R.J., Bonada, N., Cartwright, D., Chuluunbat, S., Cocks, G.V., Collins, G.E., De WaArd, J., Dean, J., Flint Jr., O.S., Hausmann, A., Hendrich, L., Hess, M., Hogg, I.D., Kondratieff, B.C., Malicky, H., Milton, M.A., Moriniére, J., Morse, J.C., Mwangi, N.F., Pauls, S.U., Gonzalez, M.R., Rinne, A., Robinson, J.L., SaloKannel, J., Shackleton, M., Smith, B., Stamatakis, A., St Clair, R., Thomas, J. A., Zamora-Munõz, C., ZiesmanN, T. \& KJeR, K.M., 2016: The Trichoptera barcode initiative: a strategy for generating a species-level Tree of Life. Philosophiical Transactions B 371, 20160025. doi: 10.1098/rstb.2016.0025

Žrvić, I., Marković, Z. \& Brajković, M., 2006: Contribution to the faunistical list of Trichoptera (Insecta) of Serbia. Acta Entomologia Slovenica 14 (1), 55-68. 
Appendix 1. List of specimens used in the phylogenetic analysis of Rhyacophila cabrakensisi and $R$. vulgaris in this study, showing life stage, origin, BOLD Sequence ID number, specimen ID, number of unique haplotypes. Specimens which genomic DNA extracted in this study are written in bold letters. Abbreviation used: ID = Identification number, BOLD = Barcode of Life data system, $\mathrm{A}=$ adult, $\mathrm{M}=$ male, $\mathrm{F}=$ female, No. = number.

\begin{tabular}{|c|c|c|c|c|}
\hline Country & Location & Specimen ID & $\begin{array}{c}\text { BOLD } \\
\text { Sequence ID }\end{array}$ & Life stage \\
\hline \multicolumn{5}{|c|}{ Rhyacophila cabrankensis Malicky, Previšić \& Kučinić, 2007} \\
\hline Croatia & spring of the River Čabranka & TRCAB_1 & CROAA089-18 & A \\
\hline \multicolumn{5}{|c|}{ Rhyacophila simulatrix McLachlan, 1879} \\
\hline Austria & St. Konrad -Hausern & НMККТ584-10 & 10HMCAD-584 & - \\
\hline Austria & St. Konrad -Hausern & HMKKT964-11 & HMCAD0111-147 & A \\
\hline Austria & Rohrwiesteich & BHMKK208-12 & 12HMCAD-042 & A \\
\hline France & Mercantour NP, Saorge E & HMKKT155-10 & 10HMCAD-155 & A \\
\hline \multicolumn{5}{|c|}{ Rhyacophila vulgaris Pictet, 1834} \\
\hline Austria & $\begin{array}{l}\text { Rankweil: Weitried/ Landesforst- } \\
\text { garten }\end{array}$ & HMKKT054-10 & 10HMCAD-054 & A \\
\hline Austria & Klostertal, Nenzigast Alpe & HMKKT128-10 & 10HMCAD-128 & A \\
\hline Austria & Seeausrinn bei Lunz & HMKКT194-10 & 10HMCAD-194 & A \\
\hline Austria & $\begin{array}{l}\text { Rankweil: Weitried/ Landesforst- } \\
\text { garten }\end{array}$ & HMKKT329-10 & 10HMCAD-329 & - \\
\hline Austria & $\begin{array}{l}\text { Rankweil: Weitried/ Landesforst- } \\
\text { garten }\end{array}$ & HМККТ330-10 & 10HMCAD-330 & - \\
\hline Austria & Seeausrinn bei Lunz & НMККТ476-10 & 10HMCAD-476 & - \\
\hline Austria & Seeausrinn bei Lunz & НMККТ477-10 & 10HMCAD-477 & - \\
\hline Austria & St. Konrad-Hausern & HMKКТ938-11 & HMCAD0111-121 & A \\
\hline Austria & Flexenpass & INTAP217-17 & PE256 & A \\
\hline Austria & Salzburg City, Thumegger Bezirk & KJTRI121-13 & 12HMCAD-131 & A \\
\hline Croatia & Kupčina, upper part, Vrabac & TRVUL_1 & CROAA031-18 & A \\
\hline Germany & $\begin{array}{l}\text { Oberallgaeu: Baeche oh Gras- } \\
\text { gehren-Azw. Balderschw. }\end{array}$ & GBMIX1704-15 & GBOL12189 & A \\
\hline Germany & Isar km 247, Hoehe Wallgau & FBAQU377-09 & BC ZSM AQU 00377 & A \\
\hline \multicolumn{5}{|c|}{ Anabolia furcata Brauer, 1857} \\
\hline Croatia & creek Jankovac & TAFUR_1 & CROAA002-18 & $\mathrm{A}$ \\
\hline
\end{tabular}

